This report was prepared as an account of work sponsored by an agency of the United S'ates Government. Neither the United States Government nos any agency thercol, nor any of their employees, makes any warranty, express or implied, or assumes any legal liability or responsibility for the accuracy, compleleness, or usefulness of any injormation, apparatus, product. or process disclosed, or represents that its use would not infringe privately owned rights. Reference hercin 10 any specific commercial product, process, of service by trade nante, trademark. manufacturer, or otherwise does not necessarily constitute or imply its endorsement, recommendation, or Iguaring by the Unilud States Government or any agency thereof. The views and apinions of authors expiessed herein do not recessarily staie or reflex those of the United Stutes Government or any agency thereof.

\title{
Ion Temperature fron Tangential Charge Exchange Neutral Analysis on the Tokamak Fusion Test Reactor
}

\author{
C.L. Fiore \\ Plasma Fusion Center, M.I.T. \\ PPPL -2475 \\ DEB8 003461 \\ Cambridge, MA 02139, USA
}

\author{
S.S. Medley, G.W. Hammett, R. Kaita, A.L. Roquemore, S.D. Scott \\ Plasma Physics Laboratory, Princeton University \\ Princeton, NJ 08544, USA
}

\begin{abstract}
Fokker-Planck simulations of the Tokamak Fusion Test Reactor (TFTR) energetic jon mode discharges were performed to evaluate the utility of deriving the central ion temperature, $T_{i}$, from deuterium neutral beam charge exchange spectra above the neutral beam injection energy. The $T_{i}$ values obtained from fitting the calculated spectra obtained from sightlines nearly tangent to the neutral beam injection radius reproduce the central ion lamperature within $\pm 10 \%$ over the full range of TFTA energetic ion mode parameters. The code simulations demongtrate that the ion temperature obtained from the high energy tangential deuterium charge exchange spectrum is insensitive to variations in the plasma density, $Z_{e} f f$, plasma current, loop voltage, and injecred neutral beam power and energy. Use of this metho' to reduce charge exchange data from TFTR energetic ion mode plasmas is demonstrated.
\end{abstract}

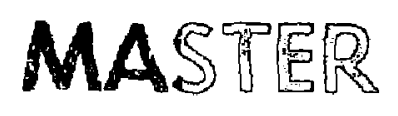




\section{Introduction}

Recent experiments using high power ( $\leq 18 \mathrm{MW}$ ) deuterium neutral beam injection into low density Tokamak Fusion Test Reactor (TFTR) deuterium plasmas have produced an energetic ion mode of operation [1]. The central ion temperatures for these plasmas measured by Doppler broadening of the FeXXV Ka line are in excess of $22 \mathrm{keV}$ [2]. Charge exchange ion temperature measurements[3] of the bulk plasma are difficult to obtain from residual hydrogen in the derterium plasma because of the low hydrogen concentration, which is typicaily $H /(H+D) \sim 1.5 \%$. The deuterium charge exchange neutral energy spectra are dominated by the deuterium neutral beam slowing-down spectra rather than a th rmal Maxwellian energy distribution, so that a method of obtaining the central ion temperature from the fast deuterium neutral spectra is desired.

In this work the feasibility of obtaining the central ion temperature of the TFTR plasma from the deuterium charge exchange neutral energy spectrum fitted above the neutral beam injection energy is explored. The solution to the Fokker-Planck equation in cylindrical geometry for beam ions near but above the neutral beam injection energy is of the form $[4] f(E) \sim \exp \left(-E / T_{\text {eff }}\right)$, where

$$
T_{c f f}=\frac{T_{i}+\left(\frac{E}{E_{c}}\right)^{1.5} T_{e}}{1+\left(\frac{E}{E_{c}}\right)^{1.5} \pm \tau_{d} 9.58 \times 10^{11} \frac{\left.Z_{b} \mid E_{b}^{*}\right\rfloor}{A_{b}}\left(\frac{E}{E_{c}}\right)^{1.5}} .
$$

In this equation $T_{i}$ and $T_{e}$ are the ion and electron temperatures, $Z_{\mathrm{b}}$ and $A_{\mathrm{b}}$ are the charge and mass of the neutral beam ions, and $E_{c}$ is the critical energy above which the effects of the electron drag on the beam ions are more important than the ion energy diffusior. $E_{c}$ is defined as

$$
E_{c}=A_{b}\left(\frac{Z]}{\overline{A_{i}}}\right)^{2 / 3} 14.8 T_{c}
$$

where

$$
\frac{[Z]}{\overline{A_{i}}}=\sum \frac{n_{i}}{\pi_{e}} \frac{Z_{i}^{2}}{A_{i}} \frac{\ln \Lambda_{i}}{\ln \Lambda_{e}}
$$

The remaining term in the denominator accounts for the effects of the toroidal electric field, where $\tau_{0}$ is the slowing-down time of ti.e fast ions, $v_{b}$ is the beam ion velocity, and $\left|\vec{E}^{*}\right|_{\text {, }}=|\vec{E}|\left(1 .-Z_{b} / Z_{\text {eff }}\right)$ where $|\vec{E}|$ is the magnitude of the electric field in Volts/cm. Thestrmi containiog the electric field is small ( $O \sim 10^{-2}$ compared to unity) and will be 
neglected in the calculation of $T_{i}$ from $T_{e / f}$. Thus the slope of the ion energy distribution fuaction above the neutral beam injection energy is determined by a balance between the energy diffusion of the ions and the electron drag, resulting in an effective teroperature which is a weighted average of the ion and electron temperatures.

In principle, the electron temperature measured from other diagnostics $[5,6]$ can be used in corjunction with the measured logarithmic slope of the deuterium charge exchange Eux plotted as a function of energy above the neutral beam injection energy to obtain the jon temperature of the plasma. Figure 1 shows a Fokker-Planck calculation of a chord-inkegrated deuterium charge exchange spectrum obtained from a tangential analyzer sightline at the neutral beam injection radius for a typical TFTR energetic ion mode discharge. The highest energy component of the injected beam was $100 \mathrm{keV}$ and the energy range from which $T_{\text {eff }}$ will be fit is $120-160 \mathrm{keV}$.

The ion temperature determined in this manner will represent the central ion temperature if the neutral beam deposition is near the plasma center (thus assuring that the neutral beam slowing down spectra results from collisions with plasma jons from the center of the plasma) and if the measured charge exchange neutral flux arises from the plasma center. The limits of plasma operating conditions for which these constraints are met so that the $T_{i}$ calculated from $T_{\text {eff }}$ corresponds to the centrai value to within $\pm 10 \%$ error must be evaluated.

The analysis above applies in the limit of $v_{\|} / v= \pm 1$ and for $E$ near the neutral beam injection energy, $\mathbb{E}_{\text {beam }}$. In TFTR the neutral beam power is injected from 12 neutral beam sources, each aimed at a slightly different tangency radius. Also, the charge exchange flux reaching the analyzer from a given sightline is integrated over a number of $v_{\|} / v$ values relative to the tangency radii of the neutral beam injectors. Errors in the ion temperature derived from the slope of the deuterium charge exchange spectrum above the neutral beam injection energy could arise from deviation of the viewing sightline from the neutral beam injection tangency radius. An optimum charge exchange sightline selected to minimize this source of error must be determined.

Even though the derivation of Eq. (1) was done in the limit of $v_{\|} / v= \pm 1$, the pitch angle scattering operator should be insensitive to energy at the high ion energies considered 
in this study. Therefore, deviation of the charge exchange analyzer sightline from the mean neutral beam injection tangency should not have a strong effect on the measured value of $T_{e f f}$. However, the intensity of the charge exchange flux arising from a particular sightline will be a strong function of the proximity to the injection radius.

Variation in the neutral beam injection energy, differences in co- and counter-moving energetic ion orbits, noncentral origin of charge exchange signal, or excessive attenuation of the charge exchange signal could result in errors in the determination of the central ion temperature from $T_{\text {eff. }}$. In this work these sources of exror will be examined using the Fokker-Planck code FPPRF [7] to calculate the expected charge exchange spectra for TFTR operating parameters characteristic of the energetic jon mode in order to ascertain the range of discharge conditions suitable for ion temperature measurement from the slowing-down spectra of the neutral beans.

\section{Plasma Parameters used in the Code Sirnulation}

A typical TFTR energetic ion mode shoi was selected to provide baseline code input parameters for the Fokker-Planck calculations of the charge exchange neutral energy spectra. These plasmas have a major radius of $2.45 \mathrm{~m}$ and minor radius of $0.8 \mathrm{~m}$. The chosen parameters where $n_{e}(r)=7.5 \times 10^{28} \times\left(1-r^{2} / a^{2}\right)^{4} \mathrm{~m}^{-3}, T_{*}(r)=6 \times\left(1-r^{2} / a^{2}\right) \mathrm{keV}$, $T_{i}=20 \times\left(1-r^{2} / a^{2}\right) \mathrm{keV}, Z_{c f f}=3.5, A_{\text {impurity }}=20, Z_{\text {impurity }}=10, I_{\text {plasma }}=0.85 \mathrm{MA}$, $V_{\text {loop }}=0.1 \mathrm{~V}$, and $B_{\text {toroidal }}=5 \mathrm{~T}$ with $10.5 \mathrm{MW}$ neutral beam power at an energy of $100 \mathrm{keV}$. The neutral density profile was caleulated with the FRANTIC code[8] and is a cylindrically symmetric function of minor radius with a central value of $n_{0}=1.5 \times 10^{12} \mathrm{~m}^{-3}$ and an edge value of $n_{0}=5 \times 10^{14} \mathrm{~m}^{-3}$. Variations from these baseline parameters were made to determine the sensitivity of the ion temperature derivation to changes in plasma discharge parameters. Table I lists the plasma parameters which were explored in this study. For most. of the code simulations, the neutral beum power was distributed equally among 12 injection tangency radii varying from $1.73 \mathrm{~m}$ to $2.25 \mathrm{~m}$, and was assumed to be fully balanced between the co and counter directions with $24 \mathrm{MW}$ unless otherwise noted. The effects of co versus counter neutral beam injection as well as variations in the energy and power of the neutral beams were also investigated.

The viewing geometry for the TFTR horizontal charge exchange analysis is shown in 
Fig. 2. The positive riewing radius is defined such that neutrals with $v_{\|} / v>0$ (гергезentative of co-moving ions, jons travelling in the direction of the plasma current) are detected while the negative sightline sees counter-moving particles.

\section{Calculation of $T_{i}$ from $T_{e / f}$}

$T_{e f f}$ is determined from measurement of the charge exchange flux at energies above the neutral beam injection energy and is given by

$$
\frac{1}{T_{e f f}}=\frac{d}{d E}\left[\ln \left(\frac{1}{\sqrt{E}} \frac{d n}{d E}\right)\right] .
$$

The value of $\mathrm{Ti}$ calculated from the slope of the distribution function above the neutral beam injection is dependent upon the electron temperature and the average charge to mass ratio of the plasma. From Eq. (1), neglecting toroidal electric field effects,

$$
T_{i} \approx T_{e f f}+\left(T_{e f f}-T_{e}\right)\left(E / E_{e}\right)^{3 / 2}
$$

The second term in Eq. (5) varies as a function of plasma radius due to the dependence on the electron temperature. Figure 3 shows the dependence of $\left(E / E_{c}\right)^{3 / 2}$ with radius for $\mathrm{E}=140 \mathrm{keV}$ (the midpoint of the energy range from which $T_{e f f}$ will be calculated) for $T_{c 0}$ values from 4 to $10 \mathrm{keV}$ with a radial profile represented by $T_{e 0}\left(1-r^{2} / a^{2}\right)^{2}$. The value of $\left(E / E_{c}\right)^{3 / 2}$ used in the code simulations corresponds to $T_{\mathrm{e} 0}=6 \mathrm{keV}$ and is $\sim 1.5-2.0$ at $r / a<0.4$ and increases rapidly at larger radii. The calculation of $T_{i}$ from $T_{e f f}$ is thus insensitive to the point from which $T_{c}$ is taken near the center of the plasma, but changes too rapidly with position at larger radii to be used to extract $T_{i}$ without a full Fokker-Planck code analysis. This point is further illustrated in Fig. 4, which shows the ion temperature, electron temperature, and $T_{e / f}$ radial profiles expected from a typical TFTR high ion temperature shot. $T_{e / f}$ lies halfway between $T_{i}$ and $T_{e}$ near the plasma center but rapidly approaches $T_{e}$ at $r / a>0.5$. This imposes the restriction that the data must arise from the plasma center in order to utilize a simple interpretation of the high energy slope of the charge exchange neutral spectra.

The difference between $T_{i}$ and $T_{e / f}$ decreases with increasing electron temperature, and $T_{i}=T_{e / f}$ when $T_{i}=T_{e}$. Fig. 5 shows $T_{e / f} / T_{i}$ as a function of $T_{e} / T_{i}$ for several values of $T_{c}$. The TFTR high ion temperature operating regime lies approximately between 
$T_{e}=5 \mathrm{keV}$ and $T_{e}=10 \mathrm{keV}$, and between $T_{i}=5 \mathrm{keV}$ and $T_{i}=30 \mathrm{keV}$. Note that $T_{e} / / T_{i}$ approaches unity as $T_{e}$ becomes large.

\section{Sensitivity to Geometrical Effects}

Derivation of the central ion temperature from the slope of the charge exchange neutral energy spectrum above the noutral beam injection energy can be affected by several geometrical factors. First, the formula used to determine $T_{i}$ from $T_{e f}$, was obtained in the limit of $v_{11} / v= \pm 1$, so that the charge excharge analyzer sightline chosen for this analysis should be tangent at the neutral beam injection radius. In TFTR the 12 neutral beams are injected at different tangency radii, ranging from $1.75 \mathrm{~m}$ to $2.25 \mathrm{~m}$, and are injected from both the co and counter directions. Secondly, as noted above, it is inportant that the data obtained froin the charge exchange neutral analyzer arise from the center of the plasma in order to siraplify the interpretation of the data. Finite ion orbit effects and the radial distribution of the background neutral density could cause the charge exchange signal to originate from the outer part of the plasma.

\subsection{Choice of Sightline}

Selection of an optimal viewing tangency for the horizontal charge exchange analyzer is dependent on several criteria. The chosen view should yield data which reproduce the central ion temperature for the widest possible variation of TFTR plasma parameters. This criterion is met by selection of a viewing tangency as near as possible to the average neutral beam injection angle, which is $1.99 \mathrm{~m}$ for the balanced injection cases considered here. Also, the available neutral flux should be maximized in the range where $T_{e / f}$ is measured, in order to give the highest possible signal-to-noise ratio. This can also be achieved by selecting a view which is tangent to the neutral beam injection. Finally the neutral particle flux obtained from the chosen sightline should originate from the central plasma region $(r / a<0.4)$.

The Fokker-Planck code was used to calculate the charge exchange spectra over a range of analyzer tangency radii from $+2.5 \mathrm{~m}$ to $-2.5 \mathrm{~m}$ for the typical TFTR shot described in Sec. 2. At each tangency radius indicated by the plotted points in Fig. 6, a spectrum similar to that shown in Fig. I was generated by the Fokker-Planck code, and $T_{e f \text {, was }}$ derived from the slope of the spectrum above the injection energy. Tesf obtained from 
the code calculations is shown as a function of sightline in Fig. 6. The ion temperature, $T_{i}$, was calculated from Eq. (5) using $T_{e f f}$ with $T_{e}$ and $E_{c}$ taken from $r / a=0.1$ and is included in that figure. The lower error bar on the ion temperature used $T_{e}$ and $E_{c}$ from $r / a=0$, and the upper from $r / a=0.2$. The calculated ion temperature is within $\pm 10 \%$ of the input ion temperature (indicated by the dashed lines in Fig. 6) for most choices of viewing radius, with the exception of the sightlines near $+2.0 \mathrm{~m}$. As will be discussed in Sec. 4.2, the use of $T_{e}$ and $E_{c}$ from a slightly larger value of $r / a \sim 0.34$ is required to yield a calculated $T_{i}$ value within $10 \%$ of the input value for the $+2.0 \mathrm{~m}$ sightline.

The expected flux of neutrals at the charge exchange analyzer is shown in Fig. 7 as a function of viewing radius. This calculation was done for the same plasma purameters as the previous figure, but with $12 \mathrm{MW}$ neutral beam power. Thre cases are presented: the calculated flux for co-injected neutral beams only; counter-injected neutral beams only; and for fully balanced injection. The high energy flux at the analyzer is maximizud near the average neutral beam injection radius for the balanced case at a vievring radius of $\pm 2.0 \mathrm{~m}$. The neutral particie flux from positive (co-viewing) radii is dominated by the co-injected neutral beam, and the flux from the negative views is predominately from the counter-injected beam.

\subsection{Source of Neutral Particle Flux}

It is important in this analysis that the high energy nert'tal flux measured by the charge exchange analyzer originates in the central region of the plasma in order to provide a measure of the central jon temperature and to insure that the uncertainty arising from the choice of $T_{e}$ ised in the caiculation of $T_{i}$ from $T_{e / f}$ is sniall. The Fokker-Planck code was used to calculate the neutral particle flux originating from nested shells in the plazma minor cross section along with the attemuation of tie flux exiting the plasma in order to determine the spatial origin of the expectel charge exchange sigual. This shell-by-shell flux calculation, which was made using the baseline TFTR discharge parameters, is shown in Fig. 8 for the $\$ 2.0 \mathrm{~m}$ viewing sightline at an energy of $128 \mathrm{keV}$ and $100 \mathrm{keV}$. The flux is peaked just outside of center for the $-2.0 \mathrm{~m}$ view and arises from a mean radius of $\langle r / a>=0.29$ at $128 \mathrm{keV}$, and $\langle r / a>=0.2$ at $160 \mathrm{keV}$. The origin of the flux seen from the $+2.0 \mathrm{~m}$ view is somewhat outside the plasma center, with a mean value from 
$\langle r / a\rangle=0.43$ at $128 \mathrm{keV}$ and $\langle r / a\rangle=0.26$ at $160 \mathrm{keV}$.

The asycometry in the positive versus negative charge exchange sightlines is reiated to differences between the co and counter beam ion trajectories, and is reduced for higher plasi:;a currents. The percentage differenc. between $T_{e f f}$ obtained trom the $-2.0 \mathrm{~m}$ sightline and that obtained from the +2.0 In view as a function of the plasma current is shown in Fig. 9. $T_{e / f}$ determined from the calculated ion energy spectrum from the $-2.0 \mathrm{~m}$ sightline does not change with increasing plasma current, while that obtained from the $+2.0 \mathrm{~m}$ sightline increases with increasing current. This results in a $12 \%$ difference between the $T_{\text {eff }}$ values obtained frem the two sightlines at $0.85 \mathrm{MA}$ which decreases to $1.5 \%$ at $2 \mathrm{MA}$.

The mean radii fo: the origin of the charge exchange flux at $128 \mathrm{keV}$ and at $160 \mathrm{keV}$ for the $\pm 2.0 \mathrm{~m}$ sightlines are plotted as a function of plasma current in Fig. 10. This plot suggests that $T_{e}$ used to calculate $T_{i}$ from $T_{\mathrm{c} f f}$ should be taken from $0.1<r / a \leq 0.29$ for the $-2.0 \mathrm{~m}$ sightline. The value of $r / a$ from which the $T_{\mathrm{e}}$ should be determined for analyzing the charge exchange flux obtained from the $+2.0 \mathrm{~m}$ sightline skould be $\mathrm{r} / \mathrm{a}=0.4$ for the lowest value of plasma current and from decreasing $\% / a$ valueg to $r / a=0.25$ with increasing plasma current.

\subsection{Neutral Density Proflle Effects}

The neutral deusity profile used for the charge exchange source in these calculations is poloidally symmetric with $n_{0}=5 \times 10^{14} \mathrm{~m}^{-3}$ at the edge and $n_{0}=1.5 \times 10^{12} \mathrm{~m}^{-9}$ at the center. The arrangement of limiters in TFTR could alter the assumption of poloidal symmetry in this calculation. A toroidal limiter is located at the inboard wall of the vacuum vessel, and a movable limiter is situated at one toroidal location at the outer plasma edge[9]. When the plasma is in contact with only the toroidal limiter, the neutral density should peak at the inside plasma edge and should be only a weak function of radius in the outer part of the flasma[10]. This will not affect the localization of the charge exchange neutral signal for the $-2.0 \mathrm{~m}$ viewpoint which already originates primarily from the center of the plasma. The $+2.0 \mathrm{~m}$ vjewpoint will become more centrally localized if the neutral density profile is peaked toward the inboard periphery of the plasma, since the contribution to the signal from the outer part of plasma is reduced relative to that from the plasma center. This is evident from comparing the symmetric neutral density 
results of Fig. 6 with Fig. 11, which shows $T_{e f f}$ and $T_{i}$ as a furiction of viewing sightline calculated with a rising neutral density profile toward the inner periphery of the plasma and a llat profile outboard of the plasma core, $R>R_{0}$.

As the plasma density is increased, cold neutrals from the plasma edge penetrate less into the plasma, giving rise to a steep gradient in the neutral species profile. In thermal charge exchange experiments this edge-enhanced neutral density profile gives extra weight to charge exchange ncutrals arising from the lower temperature plasma edge[11]. Use of the neutral beam slowing-down spectra diminishes this effect because the source of the high energy ions is localized to the region where the neutral beam ions are deposited. The neutral beam deposition does occur at slightly larger values of $r / a$ at the highest densities considered here. The mean value of $r / a$ shifts outward by $18 \%$ for the $-2.0 \mathrm{~m}$ sightline and $30 \%$ for the $+2.0 \mathrm{~m}$ sightline for the highest density case $\left(\hat{n}_{e}=1.5 \times 10^{20} \mathrm{~m}^{-3}\right.$.)

The neutral particle flux from both the $+2.0 \mathrm{~m}$ and $-2.0 \mathrm{~m}$ sightlines has heen shown to originate predominately in the central region of the plasma. The slight asymmetry found in the origin of the charge exchange flux between the $+2.0 \mathrm{~m}$ and $-2.0 \mathrm{~m}$ sightlines is most severe for the assumptions made in the baseline calculation. The asymmetry is reduced as the plasma current is increased, and if the contribution from neutral particles at the outer plasma edge is reduced.

\section{Sensitivity to Plasma Parameters}

This method of calculating the central ion temperature from the measured effective temperature can only be used on a routine basis if it is insensitive to variations in the TFTR plasma discharge conditions other than the ion and electron temperatures. The charge exchenge spectra were calculated for viewing tangency radii of $\pm 2.0 \mathrm{~m}$ using the baseline TFTR discharge parameters and changing only the value of the central ion temperature, which was varied from $4 \mathrm{keV}$ to $30 \mathrm{keV}$. The calculated value of $T_{i}$ determined from the slope of the spectrum above the neutral beam injection energy is shown in Fig. 12a, using a $T_{e}$ value taken from $r / a=0.1$ for the $-2.0 \mathrm{~m}$ sightline and from $r / a=0.34$ for the $+2.0 \mathrm{~m}$ sightline. The $T_{i}$ determined from $T_{e / \rho}$ is within $10 \%$ of the input value for the entire range of input ion temperature.

This series of code simulations was repeated for variations in a single plasma param- 
eter, the other plasma parameters remaining fixed at the baseline values, in order to tesi for errors induced by changes in the plasma operating conditions.

\section{1 wlectron Density and $Z_{\mathrm{e} f f}$}

Changes in the electron density alter the neutral beam deposition in the plasma and the attenuation of the neutral particle lux as it exits the flasma, possibly causing a shift in the point of origin of the charge exchange flux. The sinulations were done with central electron densities varying from $5 \times 10^{10} \mathrm{~m}^{-3}$ up to $1.5 \times 10^{20} \mathrm{~m}^{-3}$ with a peaked deasjty profile typical of TFTR energetic ion mode plasmas, $\left(1-r^{2} / a^{2}\right)^{4}$. The values of caiculated jon temperature were slightly lower for the highest density cases than for the baiseline case, but remained within $\pm 10 \%$ of the input value using $T_{e}$ taken from $r / a=0.1$ for the $-2.0 \mathrm{~m}$ sightline, while the values obtaired for the $+2.0 \mathrm{~m}$ sightline obtaized using $T_{c}$ taken from $r / a=0.34$ were about $20 \%$ lower than the input $T_{i}$ (Fig. 12b). The calculation was also done for a broader density profile, $7.5 \times 10^{19}\left(1-\mathrm{r}^{2} / \mathrm{a}^{2}\right) \mathrm{m}^{-9}$, with little change observed in the calculated $T_{i}$ (Fig. 12c).

The value of $Z_{\text {eff }}$ affects the rate of pitch angle scattering of the high energy ions ax well as the hydrogenic ion fraction of the plasma. A series of calculations were done with the baseline plasma parameters in which $Z_{\text {eff }}$ was varied from 2.5 to 4.5 . The calculated $x_{i}$ values generally fall within $10 \%$ of the input ion temperature using $T_{e}$ fron the values of $r / a$ noted previously for the full range of ion temperatures sampled (Fig, 12d) and over all $Z_{\mathrm{e}} f f$ values in this range.

\subsection{Plasma Current}

The plasma current used for the TFTR baseline case, $0.85 \mathrm{MA}$, is near the minimum used in neutral-beam-heating experiments. As noted in Sec. 5, increasing the plasma current affects the origin of the charge exchange flux for the positive viewing radii, causirg it to be more centrally wighted for higher currents. The plasma currert, was varied from the baseline case up to $2 \mathrm{MA}$. The ion temperature calcuidted as a function of viewing sightline is shown in Fig. 13 for $1.9 \mathrm{MA}$ plasma current. This demonstrates that the temperature derived from positive and negative sightlines is much more symmetric than in the baseline case (Fig. 6). The value of $T_{i}$ crlculated from the uegative views was waffected by changing plasma current and remained within $10 \%$ of the input value for the 
full range of infrut ion ter peratues using the previous $T_{\mathrm{e}}$ value, arising from $r / a=0.1$. The values of $T_{i}$ calculated from the positive viewpoint were within $10 \%$ of the input value (Fig. 14) if $T_{e}$ was taken from the $\sin x$ ier value of $r / a=0.2$ than had been used at lower plasma current.

\subsection{Electric Field Effects}

The derivation of the cratial ion temperature from the slope of the charge exchange spectra above the maximum neutral beam itjection energy is done assuming that the parallel electric field can be neglected. For typical TFTR ojerating parameters this leads to a possibie exror in $T_{i}$ of $1 \%$. However, the effects of the electric field ire fully included in the Fokker-Plands code caiculaticns of the neutral energy specira. The loop voltage for the energetic ion mode used as : he 'aseline case is $0.11 \mathrm{~V}$. Increasing the loop voltage by a factor of 10 to $1.2 \mathrm{~V}$ decreases the ion temperature determined from the $-2.0 \mathrm{~m}$ sightline by $8.5 \%$ and increases the ion temperature from the $+2.0 \mathrm{~m}$ sightline by $10 \%$. The clerived ion temperature for the : wo cases is shown as a function of viewing sightline in Fig. 15. Neglest of the electric field even for large changes in the loop voltage of TFTR imposes less than $10 \%$ error in the ion tempereture calculated from the high energy deuterium spectrum.

\section{Sensitivity to Neutral Beam Parameters}

The high energy deuterium neutral particle flux detected by the charge exchange analyzers derives almost entirely from neutral beam ions. It is expected that changes in the neutra vean parameters will affect the relative charge exchange flux.

The charge exchange spectra from TFTR baseline discharges were calculated with the Fokker-Plarck code for neutral beam injection powers ranging from $12 \mathrm{MW}$ up to $27 \mathrm{MW}$. Tl- $T_{i}$ values calculated from $T_{e f f}$ fell within $10 \%$ of the input ion temperatures over the full range of neutral beam powers (Fig. 16b) using $T_{e}$ values taken from $r / a=0.1$ for the $-2.0 \mathrm{~m}$ data and from $r / a=0.34$ for the $+2.0 \mathrm{~m}$ sightline.

Small variations in the neutral beam injection epergy could affect the value or the slope of the neutral beam slowing-down spectrum in the region where the $T_{e f f}$ fit is determined. Charge exchange spectra were calculated for typical variations of $\pm 10 \%$ in the neutral beam injection energy for sevezal different cases. In one case, four of the beams were 
injected with $95 \mathrm{keV}$, four with $100 \mathrm{keV}$, and four with $105 \mathrm{keV}$. Another variation was tested using all of the counter-injected beams at $90 \mathrm{keV}$ and all of the co-injected beams at $100 \mathrm{keV}$. A third calculation was done with eight of the beams at $90 \mathrm{keV}$ and four at $100 \mathrm{keV}$. The most extreme deviation of the calculated $l_{i}$ from the input value was found (Fig. 16c) when four of the beams were injected with $90 \mathrm{keV}$, four with $100 \mathrm{keV}$, and four with $110 \mathrm{keV}$. Even in this case the calculated $T_{i}$ value fell within $10 \%$ of the input value.

The high energy neutral particle flux accepted by a charge exchange analyzer with a positive sightine is frimarily from co-injected neutral beams and that detected from a negative sightline is primariiy from the counter-injected neutral beams. The ion temperaiure derived from the high energy charge exchange spectrum for all co (from the +2.0 m sightline) or all counter neutral beam injection (for the $-2.0 \mathrm{~m}$ sightline) as a function of input ion temperature is shown in Fig. 16d. The calculated ion temperature is within $10 \%$ of the input value for the full range of ion temperatures. The calculated ion temperature is also within $10 \%$ of the input value for the cases of a co-viewing sightline with all counter-injection and for a counter-viewing sightline of all co-injection. However, the absolute value of the charge exchange flux is greatly reduced it those cases.

The ion temperature calculated from $T_{\text {eff }}$ is insensitive to the total neutral beam injection power and to $\pm 10 \%$ variations in the mean neutral beam energy. It is also not sensitive to whether the neutral beams are injected in the co or counter directions.

The solution to the Fokker-Planck equation which yields Eq. (1) was solved as a linear problem by assuming that the slowing-down beam ions suffer energy diffusion through collisions only with a Maxwellian thermal population. At low plasma current $\left(I_{\mathrm{p}} \leq 1.1 \mathrm{MA}\right)$, high bearn power $\left(P_{b}=10-20 \mathrm{MW}\right)$ operation in TFTR, the calculated ratio of beam jon density to thermal deuteron density at the plasma center can reach 1:3 during balanced injection, and even 1:1 during unidirectional co-injection. Unuer these conditions a nonlinear solution to the Fokker-Planck equation may be required, which incorporates energy diffusion of weam ions through collisions with other beam ions. The nonlinear effects are beyond the scope of this analysis, and will oe addressed in a later work.

\section{Application to TFTR}

In the course of the TFTR operating period from January to July of 1987, charge 
exchange measurements were made during deuterium neutral bearn heating of deuterium plasmas to explore the application of this technique for obtaining central ion temperatire measurements from fast ion spectra as described in this paper. A mass- anc energyIt. olving $E \| B$ charge exchange analyzer $[12,13]$ was used which was remotely scannable, enabling the sightline to cover a range of tangency radii from $R_{\mathrm{tan}}=0.36-2.14 \mathrm{~m}$ in the horizontal midplane. This analyzer is des:rnated as EH 4 in Fig. 17, which shows the arrangement oi the horizontal (EH) and vertical (EV) charge exchange analyzer arrays on TFTR relative to the neutral beam injectors. Of the three horizontal analyzers, only EH 4 was equipped with a shield to suppress neutron-and gamma-induced noise signals in the microchannel plate detector [14]. Consisting of lead( $10 \mathrm{~cm}$ thick) nested inside borated polyethylere $(\sim 30 \mathrm{~cm}$ thick), the shield provided a 140 times reduction in the noise level relative to the unshielded analyzers.

Charge exchange results will be presented for two neutral-beam-heating cases which are distinguished primarily by the presence of high $\left(\left|\vec{v}_{\phi}\right|=6.8 \times 10^{5} \mathrm{~m} / \mathrm{s}\right.$, Case I) and low $\left(\left|\vec{v}_{\phi}\right|=1.5 \times 10^{5} \mathrm{~m} / \mathrm{s}\right.$, Case II) plasma toroidal rotation velocity. The tangency rudius of the analyzer sightline was $R_{\tan }=+2.0 \mathrm{~m}$ for both cases. Some parameters characterizing the discharges are listed in Table II. Tie charge exchange data will be compared with measurements from the horizontal $X$-ray crystal diagnostic [15] which used the Doppler broadening of the NiXXVII $K_{a}$ impurity line emission to obtain central plasma ion temperatures.

\subsection{Case I: High Toroidal Rotation}

Since the existence of a high plasma toroidal rotation velocity presents the most severe condition for application of this technique, this case will be discussed in detail. Co-injection only was used in this discharge with neutral beam sources $3 \mathrm{~A}, 3 \mathrm{~B}, 3 \mathrm{C}, 4 \mathrm{~B}$, and $4 \mathrm{C}$ (see Fig. 27), delivering a total injected deuterium neutral beam power of $P_{b}=10 \mathrm{MW}$. The full ewergy ranged from $90 \mathrm{keV}$ to $105 \mathrm{keV}$ with a mean value of $\left\langle E_{\text {inj }}\right\rangle=95$ keV. The beams were injected from 4.0-6.0 seconds into s toroidally limited, low density $\left(\bar{n}_{e}=0.6 \times 10^{19} \mathrm{~m}^{-3}\right)$ deuterium plasma. Following beam turn-on, the central toroidal rotation velocity rose rapidly to $\left|\vec{v}_{\phi}\right| \sim 1 \times 10^{6} \mathrm{~m} / \mathrm{s}$, but fell ab.uptly to $\left|\vec{v}_{\phi}\right|=6.8 \times 10^{5} \mathrm{~m} / \mathrm{s}$ at $t=4.4 \mathrm{~s}$ and remajned constant at this value for the duration of the beam pulse. 
The measured deuterium spectra in the energy range of $50-200 \mathrm{keV}$ is shown in Fig. 18 as a function of time during the $2 \mathrm{~s}$ ntutral-beam-heating pulse. The charge exchange data were acquired with a time resolution of 30 ms. A correction for the residual neutronand gamma-induced noise signal was also applied during the analysis. Noise correction is facilitated by using "masked" detectors which respond only to the neutron and gamma radiation to monitor the noise level as a function of time during the discharge. Using the relative neutron/gamma sensitivity of the individual charge exchange signal channels to the masked decectors determined by prior calibration, a time-dependent currection for noise on the raw charge exchange signal is obtained.

A time-slice from this spectrum at $\mathrm{t}=5.5 \mathrm{~s}$ shown in Fig. I9 illustrates two important features of the charye exchange spectra which are generally observed in the application of this technique. First, at energies modestly above the indicated mean injection energy the semi-logarithmic spectrum exhibits a linear behavior which extends to a maximum energy imposed by signal-to-noise considerations. In this example, a linear least-squares fit to the data (open circles) in the energy range of $124-187 \mathrm{keV}$ yields a measured value of $T_{e f f}=16.2 \mathrm{keV}$. Secondly, the amplitude of the charge exchange spectrum extends almost four e-foldings above tho neutron ncise level. Such strong signal levels are a significant experimental advantage of this technique. In fact with increasing injected beart power the signal and the neutron noise levels both increase, which tends to preserve the favorable signal-to-noise ratio.

The results of the analysis of the charge exchange data obtained by application of the procedures developed from the Fokker-Planck sixnulations and the toroidal rotation apalysis (Appendix A) are shown in Fig. 20. The lower three curves provide reference waveforms for the total injected beam power, $P_{b}(\mathrm{MW})$, the line-integral electron density measured in the horizontal midplane with the 1-mm interferometer, $n_{e} l\left(\times 10^{19} \mathrm{~m}^{-2}\right)$, and the time evolution of the central electron temperature, $T_{e}(k e V)$, obtained by renormalizing the Michelson interferometer waveform to the Thomson scattering data at $t=\mathbf{5} .5$ s. A parabolic-squared $T_{e}(r)$ profite was assumed, and the $E_{e}, T_{e}$ values required in Eq. (5) were evaluated at $r / a=0.34$ as prescribed by the Fokker Planck simulation results for the $+2.0 \mathrm{~m}$ analyzer sightline. The upper dashed curve shows the results of the analysis 
without correction for toroidal rotation effects. Application of the toroidal correction following the procedure given in Appendix A yields central ion temperatures from the charge exchange method shown by the solid data points. The toroidal rotation velocity in this example, $\left|\vec{v}_{\phi}\right|=6.8 \times 10^{5} \mathrm{~m} / \mathrm{s}$, is close to the maximum observed during neutralbeam-heating experiments on TFTR to date [16]. Thus, for unbalanced neutral-beambeating experiments on TFTR, toroidal rotation corrections to the central ion ternperature obtained by this charge exchange method are substantial, with corrections in the range of $50 \%$ at the highest rotation speeds. Nevertheless, it is evident that reascable agreement is found between the charge exchange results, which include the correction for toroidal rotation, and the central ion temperatures obtained from the horizontal X-ray crystal Doppler-broadening diagnostic (open data points). Preliminary analysis of an extended database consisting of approximately 70 shots covering a wide range of bearn power $\left(P_{b} \sim\right.$ 2-18 MW) and toroidal rotation speed ( $v_{\phi} \sim 1-8 \times 10^{5} \mathrm{~m} / \mathrm{s}$ ), which is in progress, continues to support this agreement.

\subsection{Case II: Low Toroidal Rotation}

The combined effects of balanced neutral beam injection and a higier electron density, both before and during the neutral beam pulse, lead to a relatively low toroidal rotation yelocity for the discharge in this case with $\left|\vec{v}_{\phi}\right| \leq 1.5 \times 10^{5} \mathrm{~m} / \mathrm{s}$ throughout the $1.5 \mathrm{~s}$ heating pulse. The charge exchange data were analyzed in the same manner as discussed in Case I, but without inclusion of toroidal rotation corrections. As shown in Fig. 21, the derived central ion temperature from charge exchange (solid data points) is in agreement with the $\mathrm{X}$-ray crystal Doppler-broadening measurement (open data points). Application of the procedure given in Appendix A yields a toroidal ratation correction to the charge exchange ion temperature of $7 \%$ for this case. The bars on the charge exchange data points in this plot show the variation in the derived ion temperature which results from imposing a \pm 0.1 change in the value of $r / a=0.34$ used to determine the magnitude of $T_{c}$ and $E_{c}$ in Eq. (5).

The above examples illustrate that the charge exchange method advanced in this paper yields ceritral ion temperature neasurements which appear to be reliable, based on the agreement to within $\pm 10 \%$ with data from the $\mathrm{X}$-ray crystal Doppler-broadening 
diagnostic. Although substantial corrections to the charge exchange data are required for discharges having high toroidal rotation velocity, a simple but adequate procedure bas ben developed to correct for this effect.

\section{Conclusions}

This study has demonstrated that the central ion temperature can be extracted from the deuterium charge exchange spectrum obtained during deuterium neutral bearn injection in TFTR energetic ion mode discharges. It has been shown that data obtained from sightlines at the mean tangency radius of the neutral beam injectors originate near the plasma center for typical TFTR operating parameters. The central ion temperature is well reproduced despite wide variations in input flasma parameters. The calculated $T_{i}$ values fall within $10 \%$ of the input values for central plasma density variations from $5 \times 10^{18} \mathrm{~m}^{-3}$ to $1.5 \times 10^{20} \mathrm{~m}^{-3}$, density profiles of $\left(1-r^{2} / a^{2}\right)^{\alpha}$ where $\alpha$ varies from 1 to $4,2.5<Z_{\text {ef } f}<$ 4.5, and plaspa curreais ranging from $0.85 \mathrm{MA}$ to $2 \mathrm{MA}$. The calculated $T_{\mathrm{i}}$ values were insensitive to neutral beam power changes from $12 \mathrm{MW}$ to $27 \mathrm{MW}$ or to $\pm 10 \%$ changes of the neutral beam injection energy about a mean value. Application of this technique to high energy charge exchange data from TFTR energetic ion mode plasmas yields ion temperature values which are in agreement with those obtained using other diagnostic methods.

\section{Appendix A: Toroidal Rotation Effects}

In TFTR the introduction of unbalanced neutral beam injection can induce large plasma toroidal rotation velocities. Rotation speeds of up to $8 \times 10^{5} \mathrm{~m} / \mathrm{s}$ bave been observed. The velocity of an ion in the rotating plasma is different from the velocity of the same ion detected by the charge exchange analyzer, both in magritude and direction. This affects assumptions made about the relative importance of the electron collis onal effects in the determination of the distribution function. In addition, the siope of the measured ion energy distribution function is modifed from its plasma frame value by the rotation.

Toroidal rotation effects have not been included in the Fokker-Planck code used in this study. The purpose of this appendix is to estimate the importance of the toroidal rotation effects in interpreting charge exchange data, and to provide a method of correcting for them. 


\section{A.1 Basis for Rotation Correction}

An energetic neutral hydrogen atorn having a velocity $\vec{v}_{i}$ exiting a plasma which rotates toroidally with velocity $\vec{v}_{\phi}$ has a velocity $\vec{v}_{\text {Jab }}$ with respect to the charge exchange analyzer given by

$$
\vec{v}_{a b}=\vec{v}_{i}+\vec{v}_{\phi} .
$$

The measured energy of this neutral, $E_{l a b}=\frac{1}{2} m_{i}\left|\vec{v}_{l a b}\right|^{2}$ where $m_{i}$ is the ion rass, is different from its energy $E_{i}$ in the plasma frame,

$$
E_{i}=E_{l a b}-2 \cos (\theta) \sqrt{E_{l a b} E_{\phi}}+E_{\phi} .
$$

Here $E_{\phi}$ is defined $\frac{1}{2} m_{\mathrm{i}}\left|\vec{v}_{\phi}\right|^{2}$ and $\theta$ is the angle between the charge exchange analyzer sightline and the direction of the plasma rotation. This energy in the plasma frame determines the effective temperature in the plasma frame,

$$
T_{e f \rho}^{\prime}=\frac{T_{i}+\left(\frac{E_{i}}{E_{c}}\right)^{2.5} T_{e}}{1+\left(\frac{E_{i}}{E_{c}}\right)^{1.5}}
$$

The distribution function in the laboratory frame is related to the distribution function in the plasma frame by

$$
f\left(E_{l a b}\right)=f\left(E_{i}\right) \frac{d E_{i}}{d E_{l a b}}=\left(1-\cos (\theta) \sqrt{\frac{E_{\phi}}{E_{i a b}}}\right) \epsilon^{-E_{i} / T_{i s s}^{\prime} . \text { eqno }(A 4)}
$$

If the distribution function in the lab frame is approximated by $f\left(E_{\mathrm{lab}}\right)=A e^{-E_{\mathrm{lab}} / T_{\mathrm{tab}}}$ where $A$ is an energy dependent constant, then in the manner of Scott[17] minimization of the error integral

$$
\epsilon\left(T_{l a b}\right)=\int_{E_{1}}^{E_{2}} d E\left(\ln \left(\frac{f\left(E, T_{e f f}^{t}\right)}{\sqrt{E}}\right)-\ln \left(\frac{\tilde{f}\left(E, T_{l a b}\right)}{\sqrt{E}}\right)\right)^{2}
$$

with respect to $T_{l a b}$ will yield an expression for $T_{l a b}$ in terms of $T_{e f f}^{\prime}$. The limits of integration in this case are the energies from which the slope of the measured distribution function will be fit to obtain $T_{\text {lab }}$. The result is

$$
T_{l a b}=\frac{T_{e f \rho}^{\prime}}{1-\cos (\theta) F(a, b) \sqrt{\frac{E_{a}^{\prime}}{T_{* \prime \prime}^{\prime}}}}
$$


where $\mathrm{a}$ and $\mathrm{b}$ are determined by the integration limits, $E_{1}=a T_{\text {eff }}^{\prime}$ and $E_{2}=b T_{\text {eff }}^{\prime \prime}$, and

$$
F(a, b)=\frac{12\left(b^{2.5}-a^{2.5}\right)-10\left(b^{1.5}-a^{1.5}\right)(a+b)}{5\left(b^{9}-a^{3}\right)-3.75\left(b^{2}-a^{2}\right)(a+b)} .
$$

Figure 22 shows $\vec{F}(a, b)$ for ranges of $a, b$ appropriate for neutral-beam-heated TFTR discharges.

Another effect stemming from the toroidal plasma rotation results from the fact that the angle of the velocity of the ions detected by the charge exchange analyzer is fixed, so that the angle between the ion velocity and the neutral beam velocity is different in the plasma and laboratory frames. The angle between the velocity of the escaping neutrals which are detected by the charge exchange analyzer and the direction of neutral bearn injection is derived from $\vec{v}_{b} \cdot \vec{v}_{i}$ and is given by

$$
\cos \left(\theta_{i b}\right)=\frac{\cos \left(\theta_{i b}\right) \sqrt{E_{l a b}}-\cos \left(\theta_{b \phi}\right) \sqrt{E_{\phi}}}{\sqrt{E_{l a b}-2 \cos (\theta)\left(E_{\phi} E_{l a b}\right)^{\frac{1}{2}}+E_{\phi}}},
$$

where $\vec{\pi}_{b}$ is the neutral beam velocity, $\theta_{10}$ is the angle between the neutral beam injection angle and the charge exchange analyzer sightline, and $\cos \left(\theta_{\mathrm{b} \phi}\right)=R_{\mathrm{tan}} / R_{0}$ is the angle between the neutral bean injection and the plasma major radius.

\section{A.2 Magnitude of the Ratation Correction}

Consider the case described in Table I, used as the baseline data set for these calculations, where $T_{e f f}=9.7 \mathrm{keV}$ was found for the $+2.0 \mathrm{~m}$ sightline. From the shell-by-shell study of the neutral particle source it was determined that $E_{c}$ should be chosen from $T_{\mathrm{c}}(r / a=0.34)$, which in this case yields $E_{\mathrm{c}}=87.5 \mathrm{keV}$. If a spatially constant toroidal rotation is applied at a velocity $\left|\vec{v}_{\phi}\right|=8 \times 10^{5} \mathrm{~m} / \mathrm{s}$, the effective energy of rotation will be $E_{\phi}=6.7 \mathrm{keV}$. The angle between the major radius and the charge exchange sightline is $\cos (\theta)=0.72$. Thus $140 \mathrm{keV}$ ions in the laboratory frame wili have a relative energy in the plasma frame oi $E_{i}=102.6 \mathrm{keV}$. This results in $T_{e f /}^{\prime}=11.43 \mathrm{keV}$. For fitting this exanple, values of $a$ and $b$ are typically 10 and 15 respectively, which gives $F(a, b)=0.28$. Application of Eq. (A6) yields $T_{\text {lab }}=13.41 \mathrm{keV}$. Use of this value to cidculate $T_{i}$ from Eq. (5) would result in $T_{i}=29 \mathrm{keV}$, whith is $45 \%$ higher than the $20 \mathrm{keV}$ input ion temperature. 
A rotation speed of $\left|\vec{v}_{\phi}\right|=5 \times 10^{5} \mathrm{~m} / \mathrm{s}$, which is more typical of unbalanced neutralbearn-injected TFTR discharges, leads in a similar fashion to a $33 \%$ overestimate of the jon temperature.

Code simulation of the rotating case was done by injecting the co-going neutral beams at a reduced energy determined by $E=E_{b}-2 \sqrt{E_{b} E_{\phi}}+E_{\phi}$, which was $55 \mathrm{keV}$ for $\left|\vec{v}_{\phi}\right|=$ $8 \times 10^{5} \mathrm{~m} / \mathrm{s}$ and $E_{b}=100 \mathrm{keV} . T_{e / f}$ determined from the resulting distribution function using energy fit limits similarly reduced from those used in the nonrotating plasma was $9.9 \mathrm{keV}$ rather than $11.43 \mathrm{keV}$ as was estimated above. Several similar calculations using different values for $\left|\vec{v}_{\phi}\right|$ resulted in a maximum deviation in $T_{e f f}^{\prime}$ from $T_{\text {eff }}$ of $4 \%$. This jrobably results from deposition of beam ions at larger major radii in the reduced energy simulations. This simulation represents one extreme in the analysis of the rotation problem because the plasma rotation in TFTR varies as a function of radius. As such, direct substitution of $T_{\text {eff }}^{\prime \prime}$ for $T_{e f f}$ results in a lower limit for the toroidal rotation correction which must be applied to any charge exchange data obtained from a rotating plasma.

For an average neutral beam injection tangency radius of $2.0 \mathrm{~m}$ and a charge exchange analyzer sightline of $2.0 \mathrm{~m}$, it can be seen from $\mathrm{Eq}$. (A8) that the ions which are detected in the analyzer from a plasma rotating with $\left|\vec{v}_{\phi}\right|=8 \times 10^{5} \mathrm{~m} / \mathrm{s}$ deviate $10^{\circ}$ from the neutral beam tangency radius, which is an effective sightline of $1.95 \mathrm{~m}$. This small deviation does not significantly affect the determination of $T_{i}$ from $T_{\ell \int f}$ for this sightline.

\section{Acknowledgements}

The authors gratefully acknowledge M. Bitter and H. Hsuan for providing the Doppler broadening $\mathrm{X}$-ray crystal ion temperature data presentea in this report. We would also like to thank K. M. Young, L. C. Johnson, and the entire TFTR group for their support of this work.

This work was sponsored by the United States Department of Energy under Contract DE-AC02-78ET51013 and Contract DE-AC02-76CHO-3073. 


\section{References}

[1]STRACHAN, J.D., BITTER, M., RAMSEY, A.T., ZARNSTORFF, M.C., ARUNASALAM, V., et. al., Phys. Rev. Lett. 58 (1987) 1004.

[2]BITTER, M., HLLL, K.W., COHEN, S., VON GOELER, S., HSUAN, H. et. al., Rev. Sci. Instrum. 57 (1986) 2145.

[3]DAVIS, S.L., MUELLER, D., KEANE, C.j., Rev. Sci. Instrum. 54 (1983) 315.

[4]GOLDSTON, R.J., PbD Thesis, Princeton University (1977). A factor of $1 / v_{b}$ in the electric field term inadvertently omitted in Eq. (29) has been included in our Eq. (1).

[5JJOHNSON, D., BRETZ, N., DIMOCK, D., GREK, B., LONG, D. , FALLADINO, R., TOLNAS, E., Rev. Sci. Instrum. 57 (1986) 1856.

[6]TAYLOR, G., EFTHIMION, P.C., MCCARTHY, M.P., FREDD, E., CUTLER, R.C., Rev. Sci. Instrum. 57 (1986) 1974.

[7]HAMMETT, G.W., PhD Thesis, Princeton University (1985); also GOLDSTON, R.J., PhD Thesis, Princeton University (1977); also CORDEY, J.G., Nucl. Fusion 16 (1976) 499.

[8]TAMOR, S.J., J. Comput. Phys. 40 (1981) 104.

[9]CECCHI, J., J. Nucl. Mater. 128-129 (1984) 1.

[10]HEIFETZ, D.B., LANGER, W.D., EHRHARDT, A.B., "Three Dimensional CaIculations of the Transport of Netiral Hydrogen and Molecular Impurities in TFTR," (Proc. 12th European Conf. on Controlled Fusion and Plasma Physics, Budapest, 1985), Vol. 1, EPS (1985) 183.

i11jPARSONS, C.R., MEDLEY, S.S., Plasma Phys. 16 (1974) 267.

[12]ROQUEMORE, A.L., GAMMEL, G., HAMMETT, G.W., KAITA, R., MEDLEY, S.S., Rev. Sci. Instrum. $5 \theta$ (1985) 1120.

[13]KAITA, R., HEIDBRINK, W.W., HAMMET, G.W., CHAN, A.A., ENGLAND, A.C., et. al., Nucl. Fusion 28 (1986) 863.

[14]MEDLEY, S.S., PERSING, R., Rev. Sci. Instrum. 52 (1981) 1463.

[15]HILL, K.W., BITTER, M., TAVERNIER, M., DIESSO, M., VON GOELER, S., Rev.

Sci. Instrum. 56 (1985) 1165.

[16]BITTER, M., ARUNASALAM, V., BELL, M.G., BOSCH, S., BRETZ, N.L., 
BUDNY, R., et. al., "Higk Power Neutral Beam Heating Experiments on TFTR with Balanced and Unbalanced Momentum Input," (Proc. 14th European Conf. on Controlled Fusion and Plasma Physics, Madrid, 1987). To be published in Plasma Physics and Controlled Fusion.

[17]SCOTT, S.D. PhD Thesis, MIT 1983. 
Table I. Plasma Paramete:s Used in the Simulations

TFTR High Ion Energy Mode Baseline Shot Based on \#26608

$T_{e}(r)=T_{e 0} \times\left(1-r^{2} / c^{2}\right)^{2} \mathrm{keV}, T_{e 0}=6 \mathrm{keV}$

$T_{i}(r)=T_{i 0} \times\left(1-r^{2} / a^{2}\right)^{2} \mathrm{keV}, T_{i 0}=20 \mathrm{keV}$

$n_{e}=n_{e 0} \times\left(1-s^{2} / a^{2}\right)^{4}, n_{e 0}=7.5 \times 10^{19} \mathrm{~m}^{-3}$

$F_{\text {beam }}=10.5 \mathrm{MW}$ (24 MW, balanced injection used in simulations)

$E_{\text {b:am }}=100 \mathrm{keV}$

$Z_{\text {eff }}=3.5$

$A_{\text {imp }}=20$

$Z_{\text {jmp }_{p}}=10$

$n_{0}(r / a=0)=1.5 \times 10^{12} \mathrm{~m}^{-9}, n_{0}(r / a=1)=5.5 \times 10^{14} \mathrm{~m}^{-3}$, FRANTIC profile

$B_{\text {toroidal }}=5.1 \mathrm{~T}$

$I_{\text {plaama }}=0.85 \mathrm{MA}$

$V_{\text {loop }}=0: 1 \mathrm{~V}$

Variation of Parameters Use 3 in the Simulations

$T_{\varepsilon}(r)=T_{e 0} \times\left(1-r^{2} / a^{2}\right)^{2} \mathrm{keV}, T_{e 0}=6 \mathrm{keV}$

$T_{i}(r)=T_{i c} \times\left(1-\tau^{2} / a^{2}\right)^{2} \mathrm{keV}, 4<T_{i 0}<30 \mathrm{keV}$

$n_{e}=n_{e 0} \times\left(1-r^{2} / a^{2}\right)^{\alpha}, 5 \times 10^{19}<n_{e 0}<1.5 \times 10^{20} \mathrm{~m}^{-3}, \alpha=1, \alpha=4$

$12 \mathrm{MW}<P_{\text {beam }}<27 \mathrm{MW}$, balanced, all co, all counter

$90 \mathrm{keV}<E_{\text {beam }}<110 \mathrm{keV}$, equal and mixed energies

$2.5<Z_{\text {eff }}<4.5$

$A_{i m p}=20$

$Z_{\text {imp }}=10$

$n_{0}(r / a=0)=1.5 \times 10^{12} \mathrm{~m}^{-3}, n_{0}(r / a=1)=5.5 \times 10^{14} \mathrm{~m}^{-3}$, FRANTIC profile

$B_{\text {toroidal }}=5.1 \mathrm{~T}$

$0.85 \mathrm{MA}<I_{\text {plaema }}<2 \mathrm{MA}$

$0.1 \mathrm{~V}<V_{\text {lcop }}<1.1 \mathrm{~V}$ 
Table II. Plasma Parameters for the Experimental Results

$\begin{array}{lll}\text { Parameter } & \text { Case I } & \text { CaseII } \\ & (\# 31457) & (\# 30655) \\ I_{p}(\mathrm{MA}) & 0.9 & 1.1 \\ B_{t}(\mathrm{~T}) & 4.8 & 4.8 \\ \mathrm{R}(\mathrm{m}) & 2.45 & 2.45 \\ \mathrm{a}(\mathrm{m}) & 0.8 & 0.8 \\ P_{b}(\mathrm{MW}) & 10.0 & 13.2 \\ P_{\mathrm{co}}(\mathrm{MW}) & 10.0 & 7.0 \\ P_{\mathrm{etr}}(\mathrm{MW}) & 0.0 & 6.2 \\ \text { Cofrac* } & 1.0 & 0.06 \\ \left|\vec{v}_{\phi}\right|(\mathrm{m} / \mathrm{s})^{* *} & 6.8 \times 10^{5} & 1.5 \times 10^{5} \\ \bar{n}_{e}, \operatorname{target}\left(\mathrm{m}^{-3}\right) & 0.6 \times 10^{18} & 1.1 \times 10^{19} \\ \bar{n}_{e}, \text { beam }\left(\mathrm{m}^{-3}\right) & 1.6 \times 10^{19} & 2.8 \times 10^{19}\end{array}$

- Cofrac $=\left(P_{c o}-P_{c t r}\right) /\left(P_{c o}+P_{c t r}\right)$ where $P_{c o}, P_{c t-}$ is the co- and counter-injected beam power respectively.

-"Representative value during the neutral-beam-heating pulse. 


\section{Figure Captions}

Figure 1. Folkker-Planck calculation of the deuterium charge exchange neutral spectrum from the $-2.0 \mathrm{~m}$ viewing sightline during deuterium neutral be um injection for a baseline energetic ion mode discharge. $T_{i}=20 \mathrm{keV}, T_{e}=6 \mathrm{keV}, n_{e}=7.5 \times 10^{19}\left(1-r^{2} / a^{2}\right)^{4} \mathrm{~m}^{-3}$, $Z_{\text {eff }}=3.5, I_{\text {plapma }}=0.85 \mathrm{MA}, P_{\text {beam }}=24 \mathrm{MW}, B_{\text {toroida! }}=5.5 \mathrm{~T}, V_{l}=0.11 \mathrm{~V}$.

Figure 2. Orientation of sightline tangency radii for ch. rge exchange neutral code simulation on TFTR. Positive sightlines view co-going neutrals while negative sjghtlines see counter-moving neutrals. The plasma major radius is $R_{0}=2.45 \mathrm{~m}$, and simulations were done for $-2.5<R_{\text {tan }}<+2.5 \mathrm{~m}$.

Figure 3. The critical energy for determination of the relative contribution of the ion and electron temperatures to $T_{e / /}$ as a function of radius. $T_{e}=T_{e 0}\left(I-r^{2} / a^{2}\right), T_{e 0}=4,5,6$, 8 , and $10 \mathrm{keV}, E_{0}=140 \mathrm{keV},[Z] / A_{i}=1 / 2, A_{b}=2$.

Figure 4. $T_{i}(r), T_{e}(r), T_{e f f}(r)$ for the baseline high ion energy mode discbarge, showing the difference between $T_{e f f}$ and $T_{i}$ as a function of plasma radius.

Figure 5. $T_{e f f} / T_{i}$ as a function $T_{e} / T_{i}$ for $T_{e}=1,5,9,13$, and $17 \mathrm{keV}, T_{e}<T_{i}<30 \mathrm{keV}$. The batched area shows trie typical operating regime for neutral-beam-heated discharges in TFTR.

Figure 6. $T_{e / f}$ and $T_{i}$ calculated trom $T_{e f f}$ using $T_{e}$ at $r / a=0.1$ as a function of charge exchange analyzer viewing sightline. The lower error bar is from $T_{e}$ for $r / a=0$. and the upper error bar is with $T_{e}$ from $r / c=0.2$.

Figure 7. Natural logarithm of the calculated neutral particle effux from the plasma as a function of viewing sightline at $128 \mathrm{keV}$ for all co, all counter, ard balanced neutral beam injection. $P_{b}=12 \mathrm{MW}, T_{i}=12 \mathrm{keV}$, and all other fliam ters are from the baseline TFTR energetic ion mode discharge.

Figure 8. Calculated neutral particle efflux from the plasma for the $\pm 2.0 \mathrm{~m}$ sightiines as a function of position of origiu for $128 \mathrm{keV}$ neutrals and $160 \mathrm{keV}$ neutrals. All paramenars are from the TFTR energetic ion mode baseline discharge. 'The mean origin of flux for the $+2.0 \mathrm{~m}$ sightline is $2.72 \mathrm{~m}(r / a=0.43)$ at $128 \mathrm{keV}$, and $2.58 \mathrm{~m}(\mathbf{r} / a=0.26)$ at $160 \mathrm{keV}$. The trean origin of flux for the $-2.0 \mathrm{~m}$ sightline is $2.46 \mathrm{~m}(\mathrm{r} / a=0.29)$ at $128 \mathrm{keV}$, and $2.44 \mathrm{~m}(r / a=0.2)$ at $160 \mathrm{keV}$. 
Figure 9. Percentage asymmetry betrieen $T_{e f \rho}$ calculated for $\pm 2.0 \mathrm{~m}$ sightlines as a function of plasma current. All other parameters are from the TFTR enargetic ion mor's baseline discharge.

Figure 10. Mean origin of the calculated neutral particle lux from the plasma for sightlines at $\pm 2.0 \mathrm{~m}$ at neutral energies of $128 \mathrm{keV}$ and $160 \mathrm{keV}$ as a function of plasnia current.

Figure 11, $T_{e f f}$ and the ion temperature derived from $T_{e f f}$ as a function of viewing sightline calculated with an asymmetric neutral density scurrs, baving a marimur of $5 \times 10^{14} \mathrm{~m}^{-3}$ at the inner plasma edge, decreasing to a minimu $\pi$ of $2 \times 10^{12} \mathrm{~m}^{-3}$ at the plasma center, and extending to the outer plasma edge. All other parameters are from the TFTR energetic ion mode baseline discharge.

Figure 12. $T_{i}$ calculated from $T_{e / \rho}$ as a function of the central ion temperature uzed in the Fokker-Planck alculation. $T_{i}$ from the $-2.0 \mathrm{~m}$ sightline are calculated with $E_{c}$ and $T_{e}$ from $r / a=0.1$ and the $+2.0 \mathrm{~m}$ sightline from $r / a=0.34$. Plasma parameter scenarios correspond to a) the TFTR energetic ion mode baseline case, b) high electron density $\left.\left(n_{e 0}=1.5 \times 10^{20} \mathrm{~m}^{-3}\right), c\right)$ broad electron density profile, $n_{e}=7.5 \times 10^{18}\left(1-r^{2} / a^{2}\right) \mathrm{m}^{-3}$, and d) $Z_{e / f}=4.5$. All unmentioned parameters for each case are from the TFTR energetic jon mode baseline discharge.

Figure i3. $T_{i}$ calculated from $T_{e f f}$ as a function of viewing sightline for a plasma current of 1.9 MA. The values derived from the positive and negative sightlines are nearly symmetric. All other parameters are from the TFTR energetic ion mode baseline discharge.

Figure 14. $T_{i}$ derived from $T_{e f f}$ as a function of the input value of $T_{i}$ used in the FokkerPlanck calculation for a plasma current of 2 MA. All other parameiers are from the TFTR high ion energy mode baseline discharge.

Figure 15. $T_{i}$ calculated from $T_{e / f}$ as a function of viewing sightline for an artificially bigh loop voltage $(1.1 \because$ ) case compared to the TFTR energetic ion mode baseline case with loop voltage $0.11 \mathrm{~V} . T_{i}$ obtained from the $-2.0 \mathrm{~m}$ sightline is d screased $8.5^{\mathrm{o}} \mathrm{v}$ and $T_{i}$ obtained from the $+2.0 \mathrm{~m}$ sightline is increased $10 \%$ over the baseline discharge. All other parameters are frotn the TFTR energet: $\_$ion mode baseline discharge.

Figure 16. $T_{i}$ derived from $T_{e / f}$ as a function of the input value of $T_{i}$ used in the FokkerPlanck calculation for different neutral beam injection parmmeters. These are a! the TFTR 
energetic ion mode baseline case, b) $12 \mathrm{MW}$ balanced injected beam power, c) mixed neutral beam energies, four at $90 \mathrm{keV}$, four at $100 \mathrm{keV}_{1}$ and four at $110 \mathrm{keV}$, and d) $12 \mathrm{MW}$ all co injected beams viewed from the $+2.0 \mathrm{~m}$ sightline and $12 \mathrm{MW}$ all counter injected beams viewed from the $-2.0 \mathrm{~m}$ sightline. All other parameters are from the TFTR energetic in mode baseline discharge.

Figure 17. Plan-view schematic of the TETR showing the arrangement of the charge exchange analyzer arrays and the neutral beam injectors.

Figure 18. Measured deuterium spectra in the energy range of $50-200 \mathrm{keV}$ during coinjection of deuterium neutral beams from 4.0-6.0 $\mathrm{s}$ into a deuterium plasma.

Figure 19. Deuterium charge exchange spectrum at $t=5.5 \mathrm{~s}$ and the simultaneously messured neutron- and gamma-induced noise level. A linear least-squares fit to the data (open circles) in the energy range of $\mathrm{E}=124-187 \mathrm{keV}$ yields $T_{e f f}=16.2 \mathrm{keV}$.

Figure 20. Comparigon of the central ion temperature from charge exchange corrected for toroidal rotation effects (circles) with borizontal X-ray crystal Doppler broadening data (squares). The central rotation velocity in the case was $6.8 \times 19^{5} \mathrm{~m} / \mathrm{s}$. The upper dashed curve corresponds to the charge exchange data without correction for toroidal rotation. The lower curves show the total injected beam power, the line-integral electron density from the 1-mm interietometer, and the central electron temperature from the Michelson interferometer renormalized to the Thomson scattering measurement at $t=5.5 \mathrm{~s}$.

Figure 21. Comparison of the central ion temperature measured by charge exchange (solid circles) and X-ray crystal Doppler broadening (open circles) for a discharge with low toroidal rotation velocity $\left(\left|\vec{v}_{\phi}\right| \leq 1.5 \times 10^{5} \mathrm{~m} / \mathrm{s}\right)$. The toroidal rotation correction to the charge exchange data is small $(\leq 7 \%)$ and has not been applied to the data as shown. Figure 22. $F(a, b)$ to be used in analysis of the effects of toroidal rotation on the high ion energy spectra obtained from TFTR discharges during unbalanced neutral beam injection. $F$ is calculated for $6<a<11$ and for $6<b<20$. 
- $87 \times 0517$

$N$

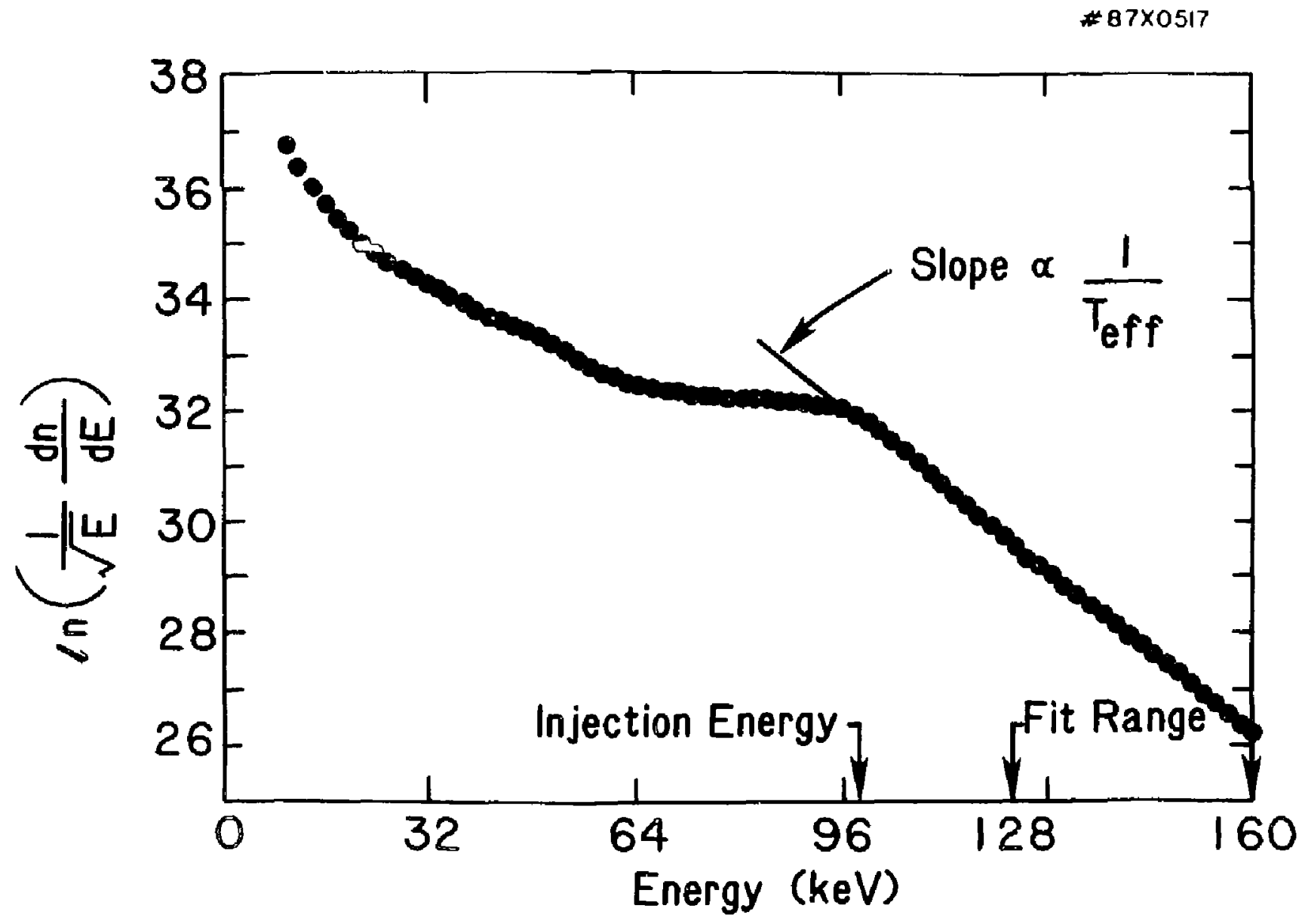




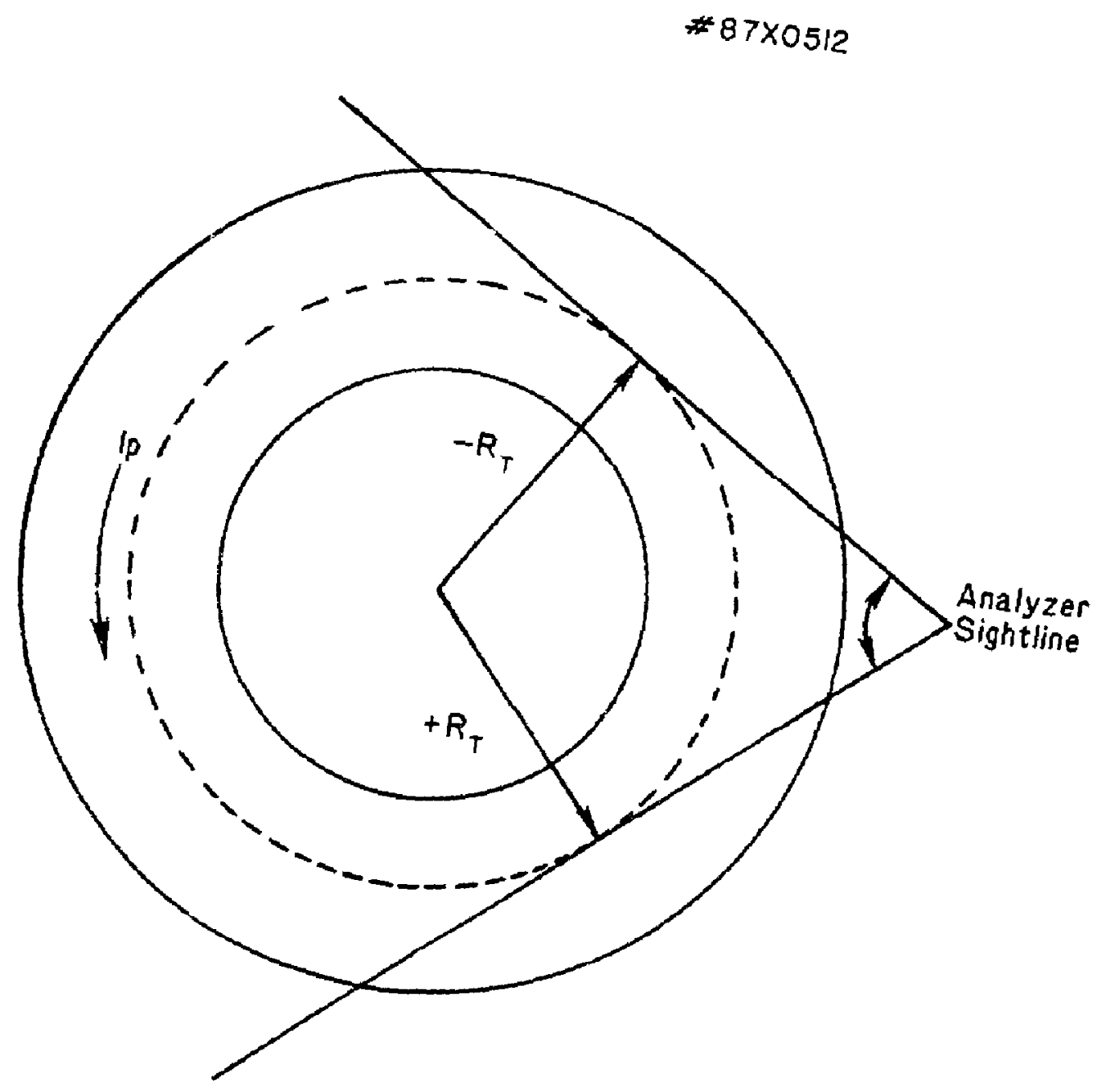

Fig. 2 


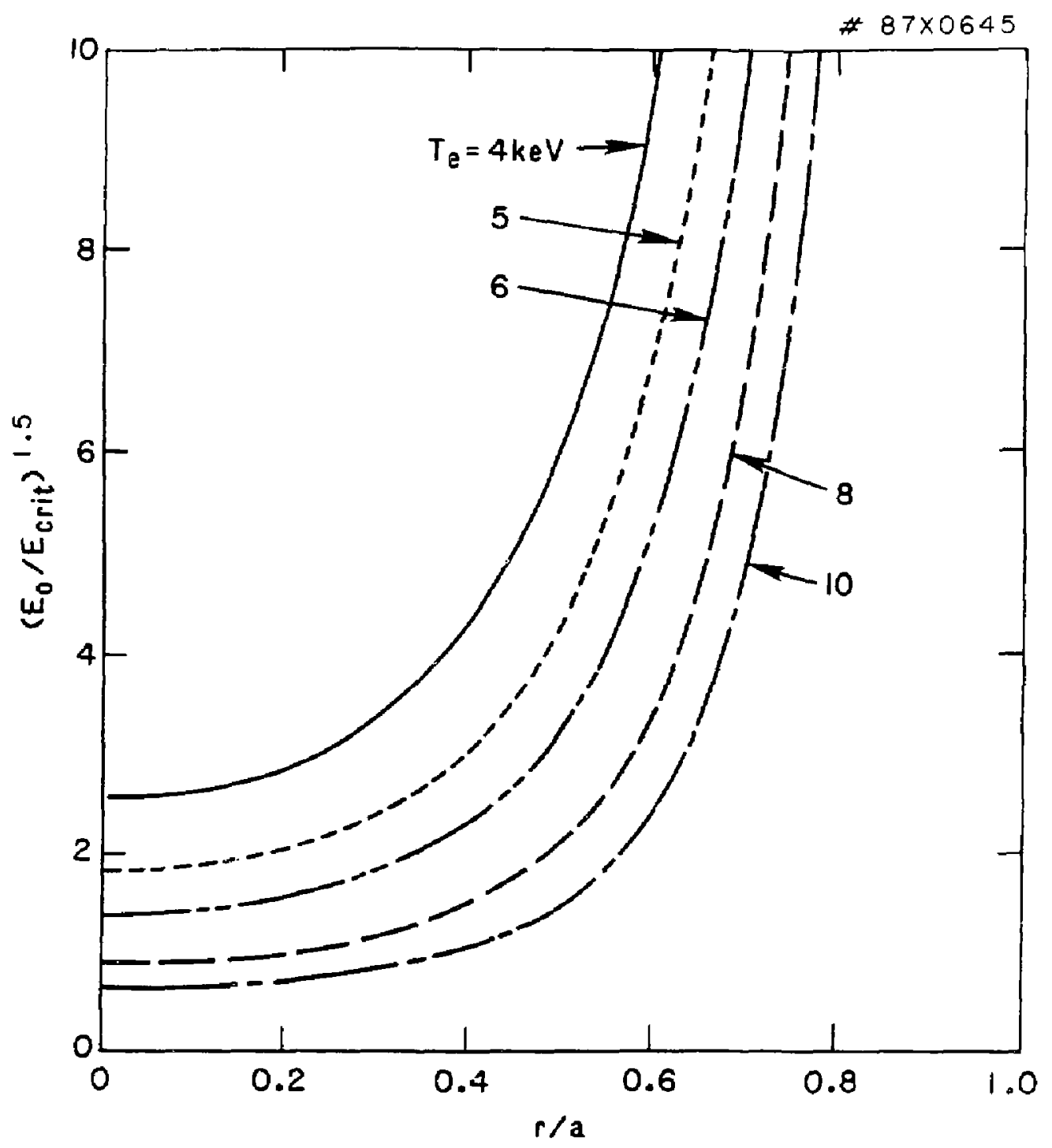

Fig. 3 
\#87X0516

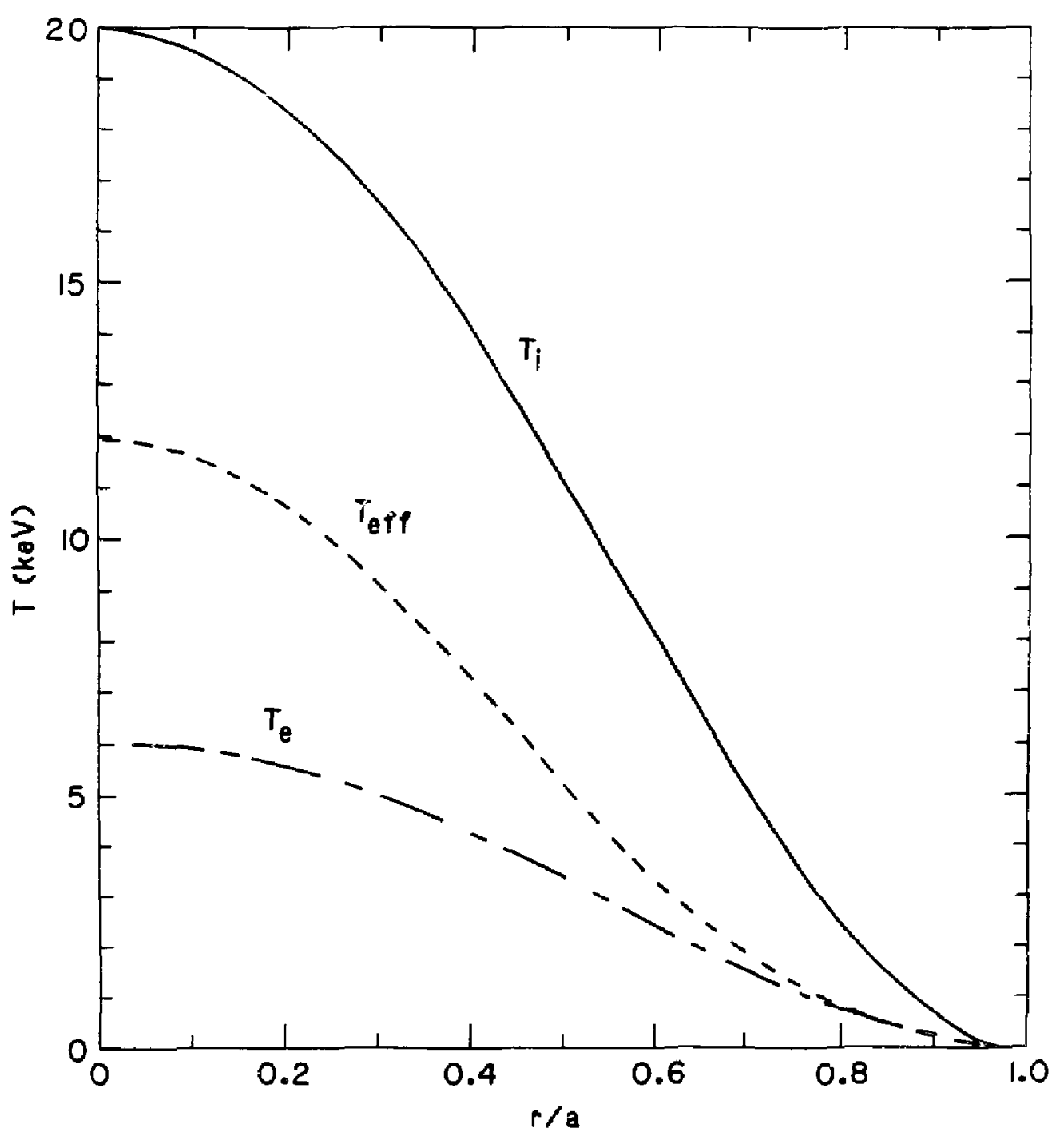

Fig. 4 


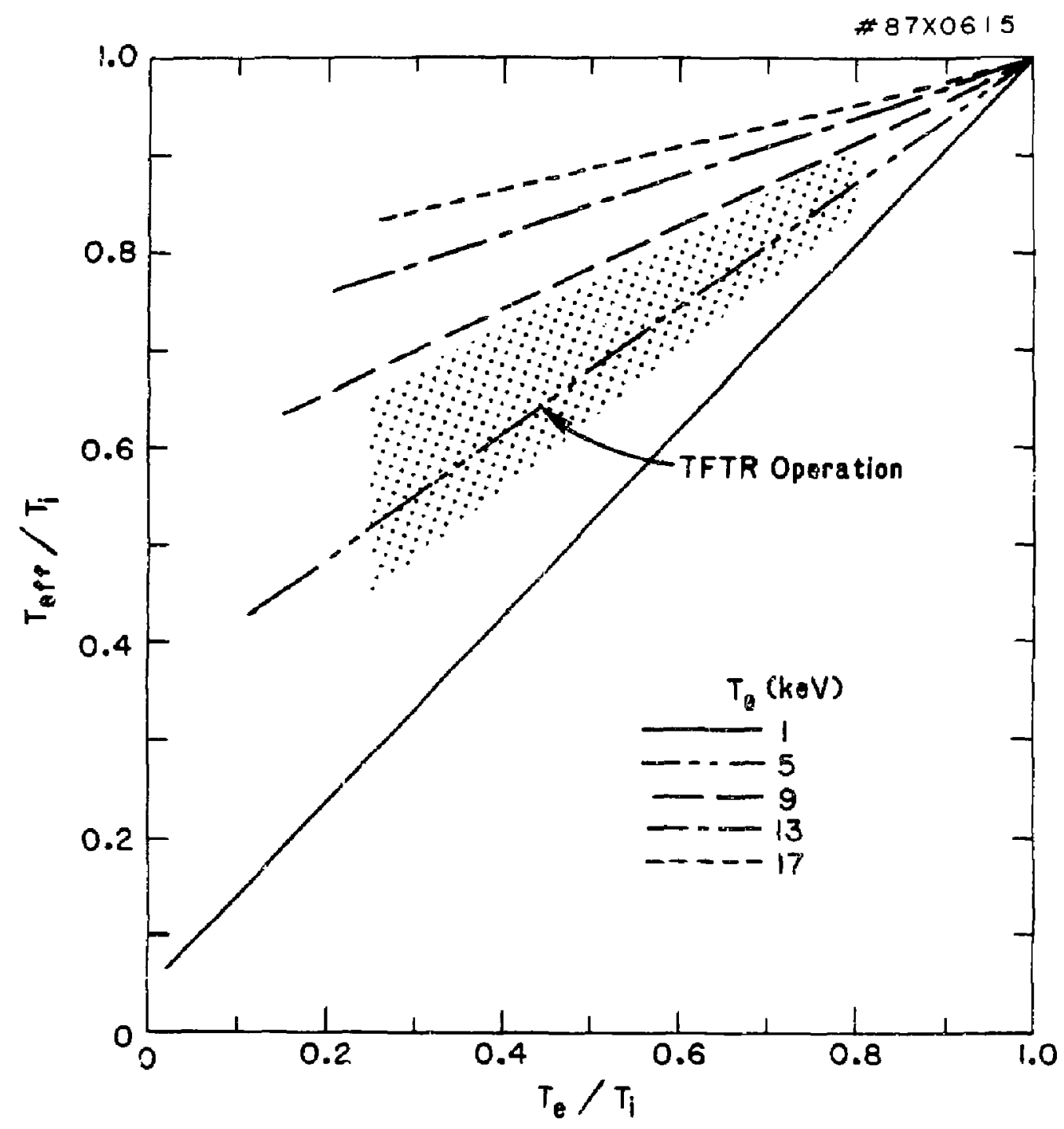

Fig. 5 
\#87X0590

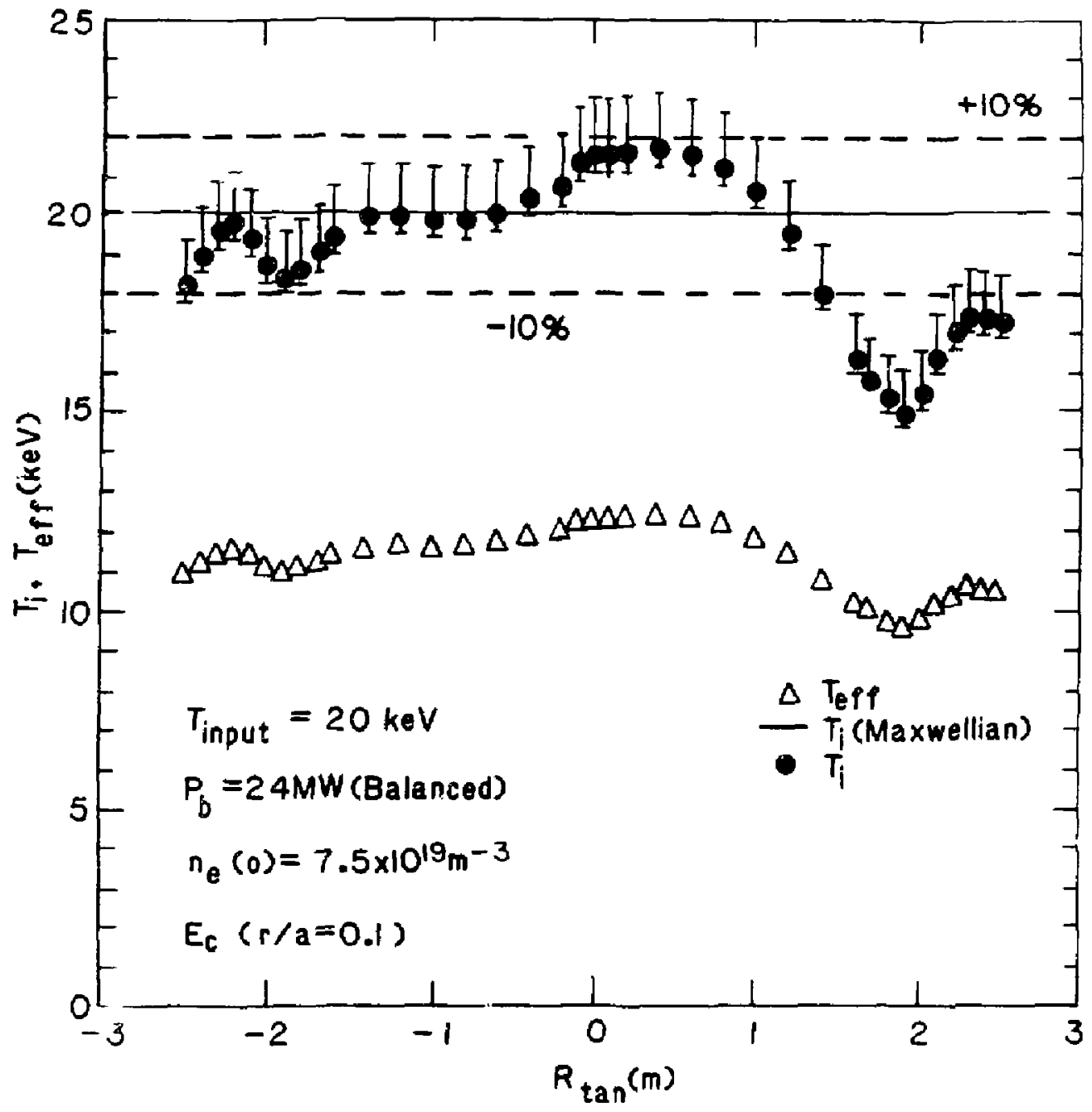

Fig. 5 
$\# 87 \times 0514$

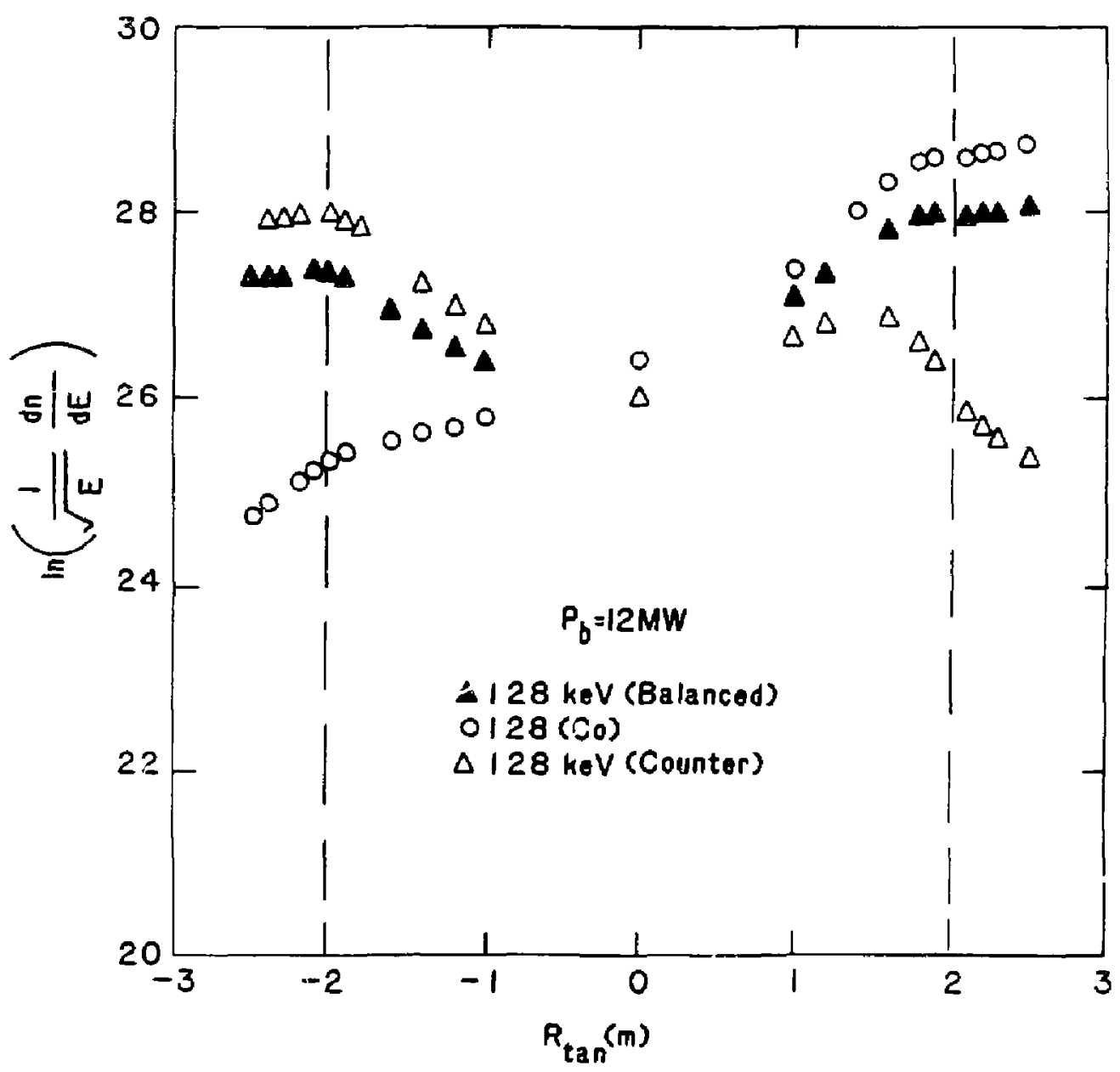

Fig. 7 

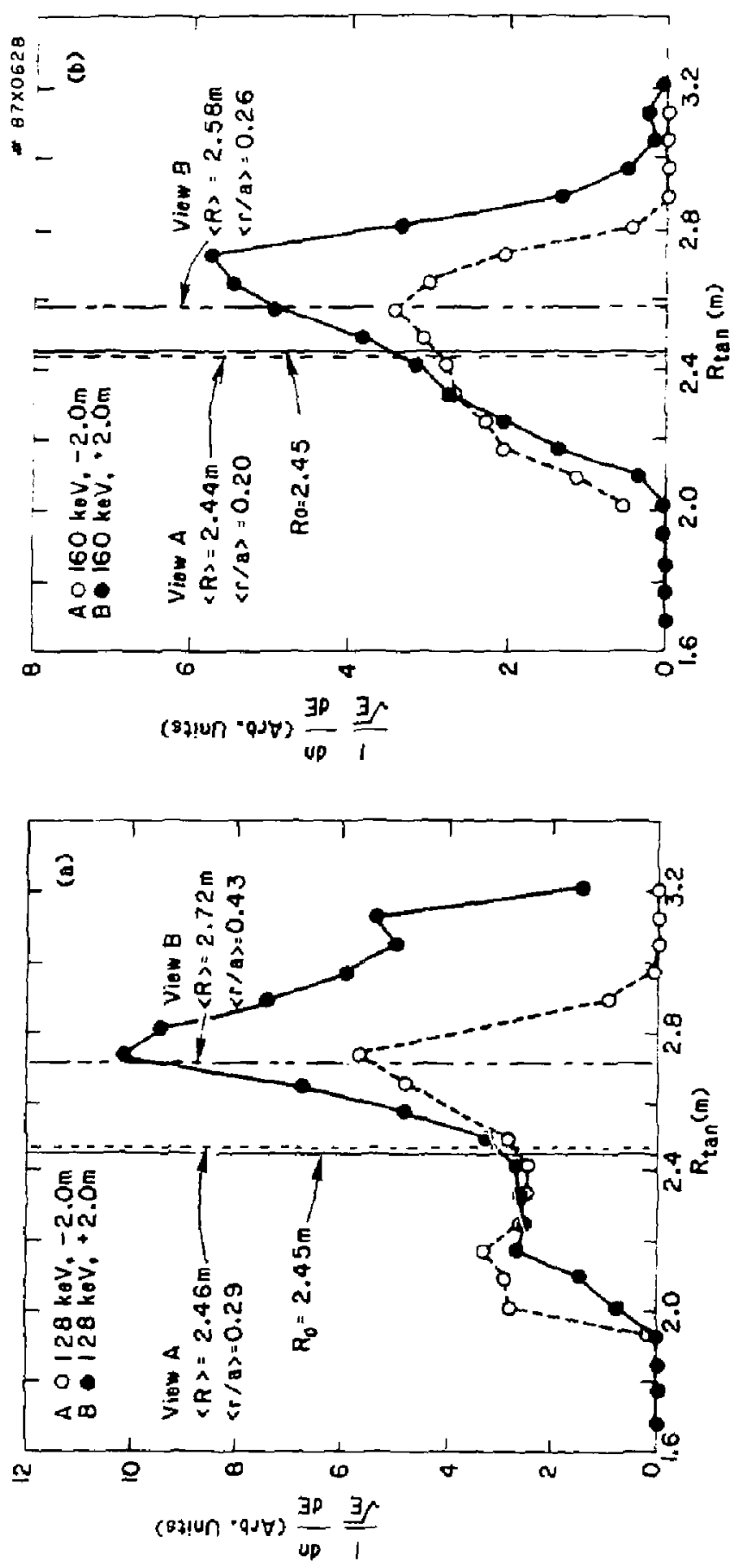


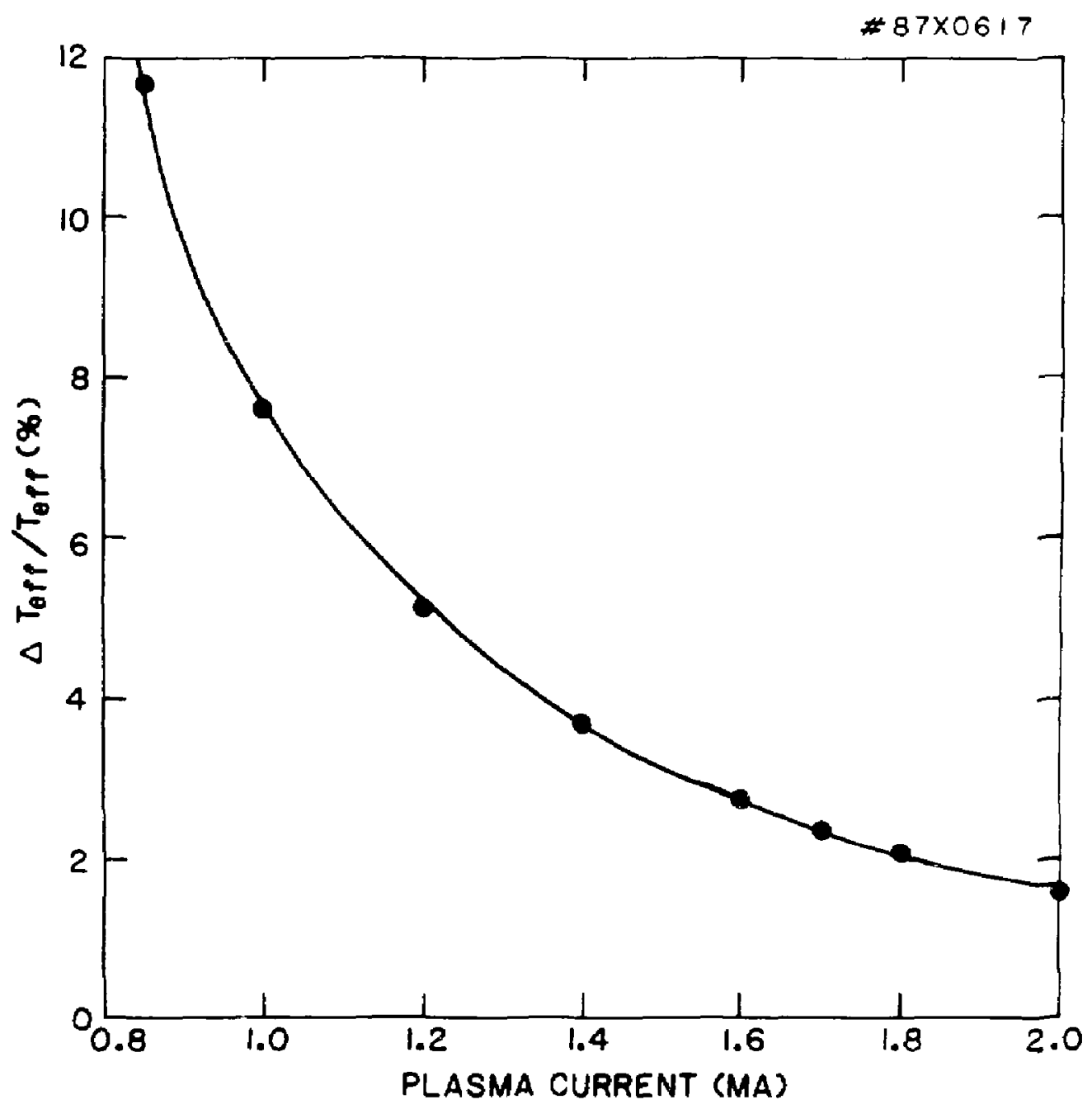

Fig. 9 


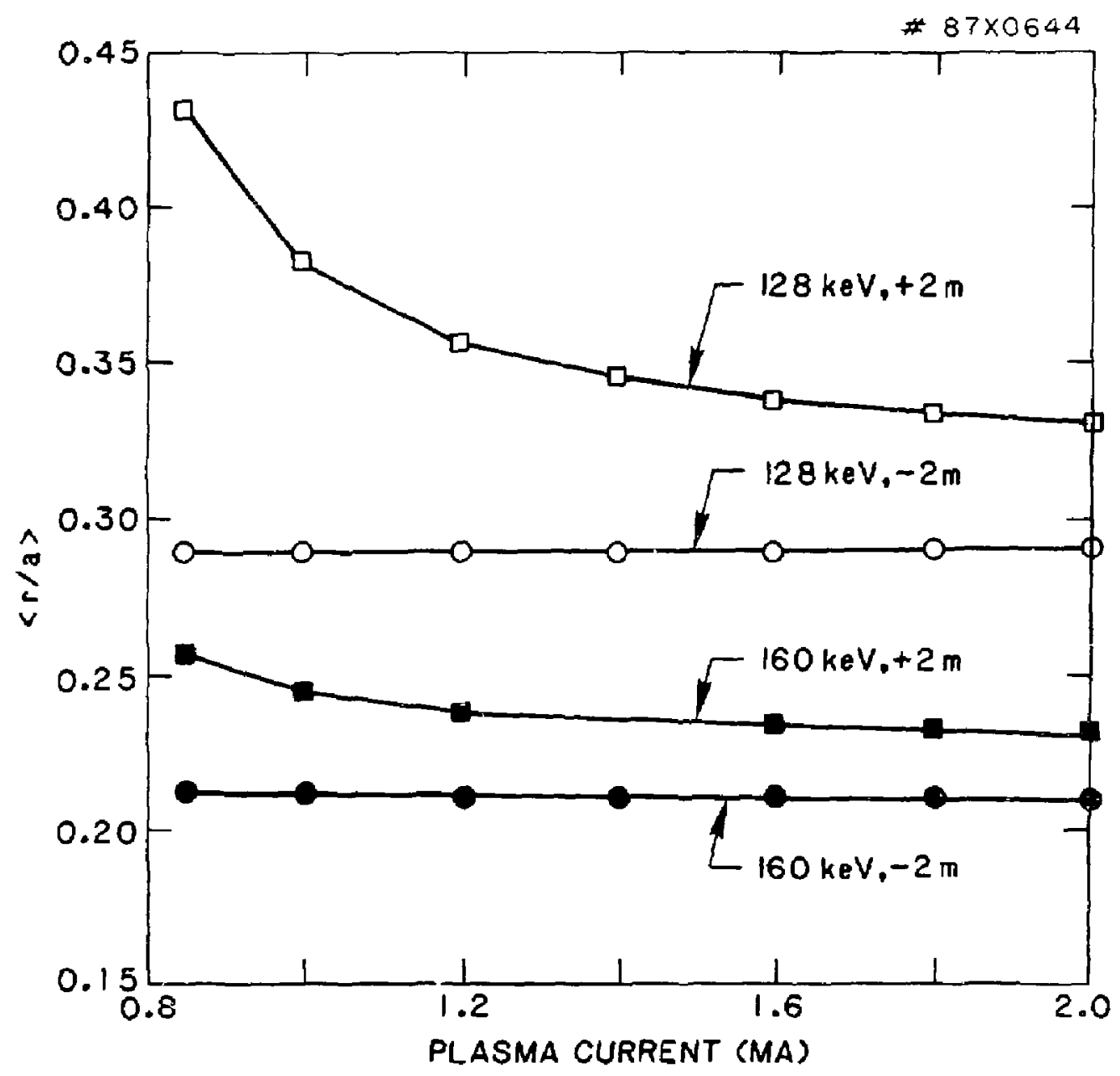

Fig. 10 


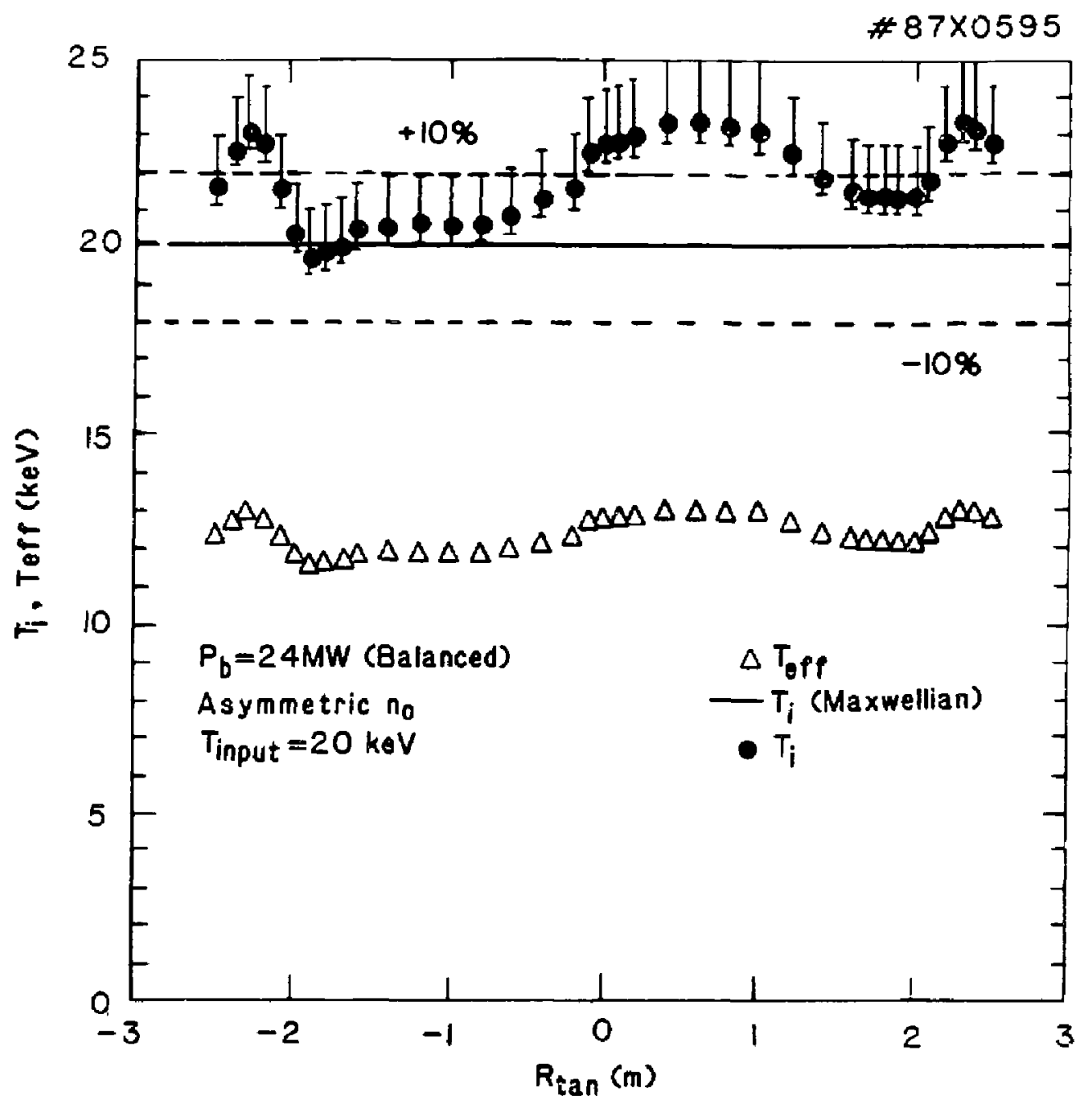

Fig. II 

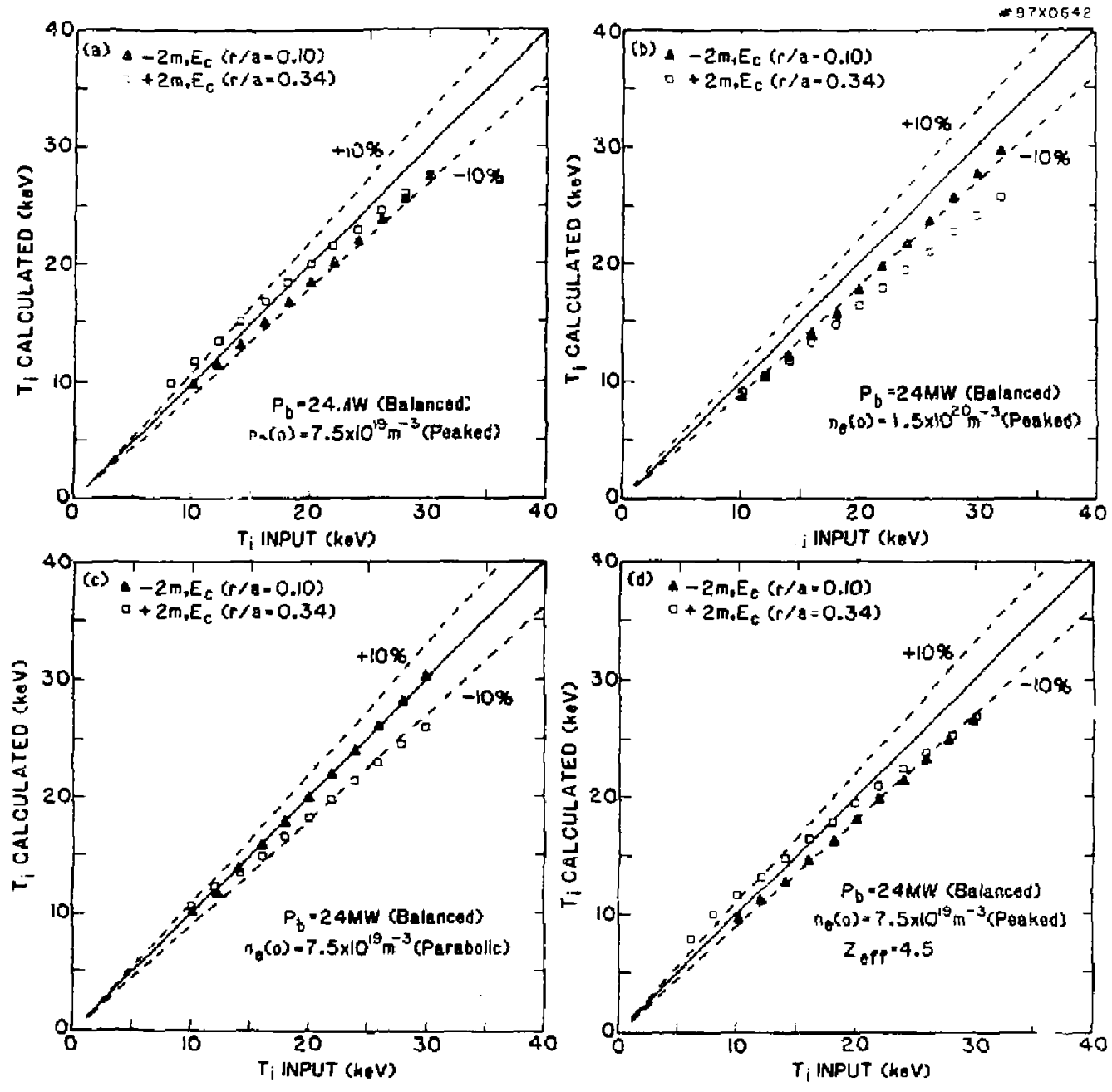

Fig. 12 


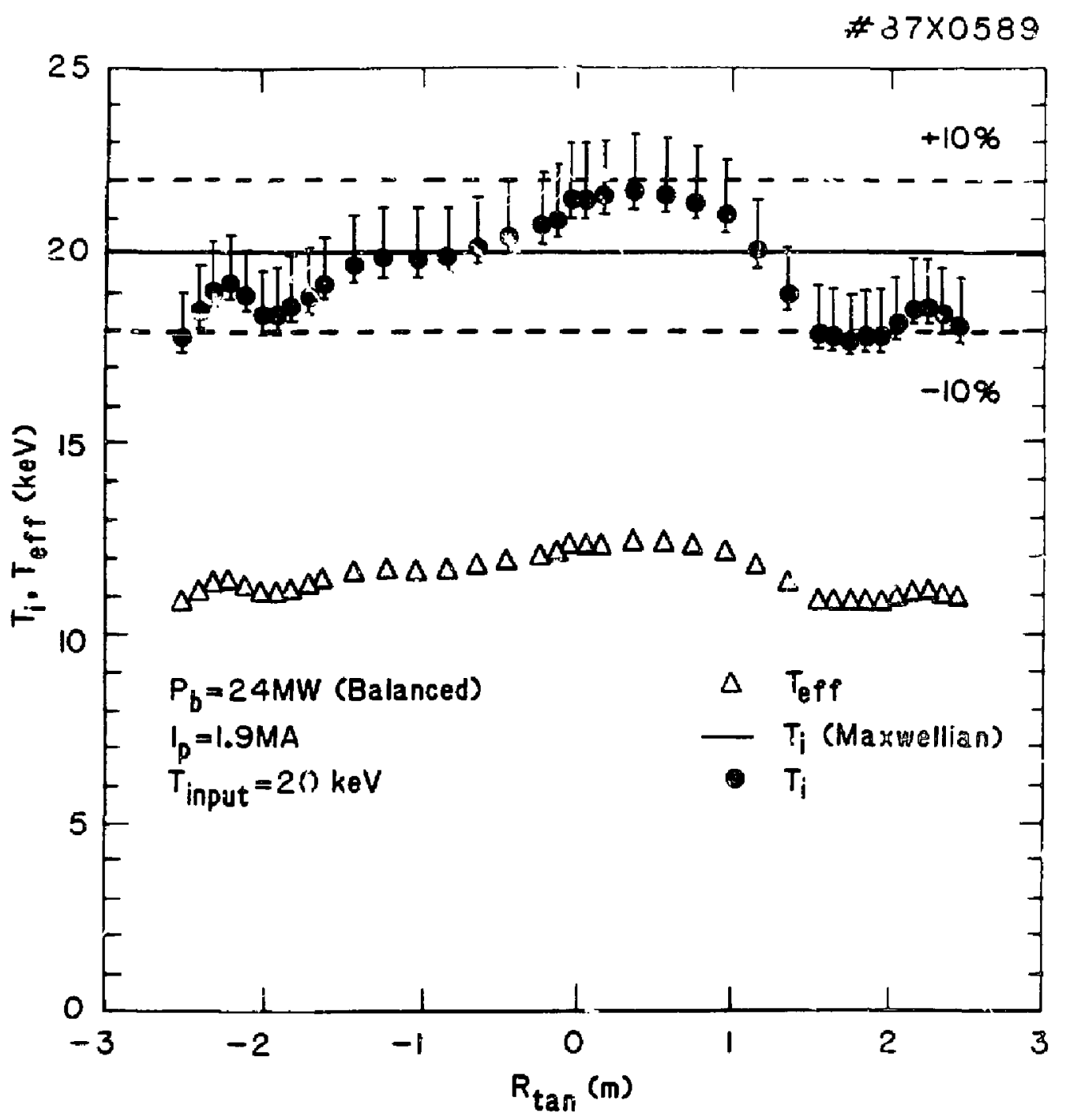

Fig. 13 
\# $87 \times 0591$

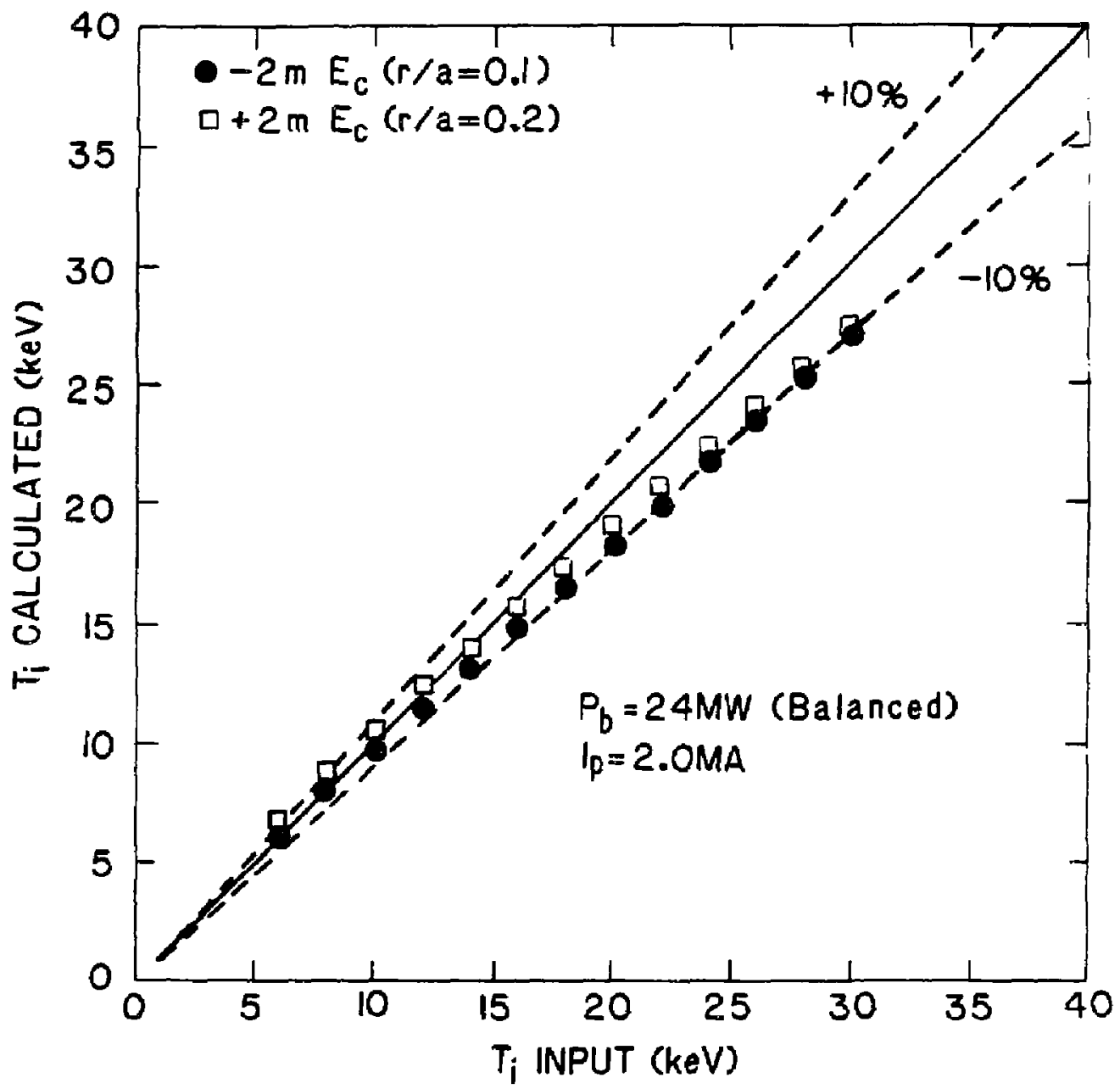

Fig. 14 


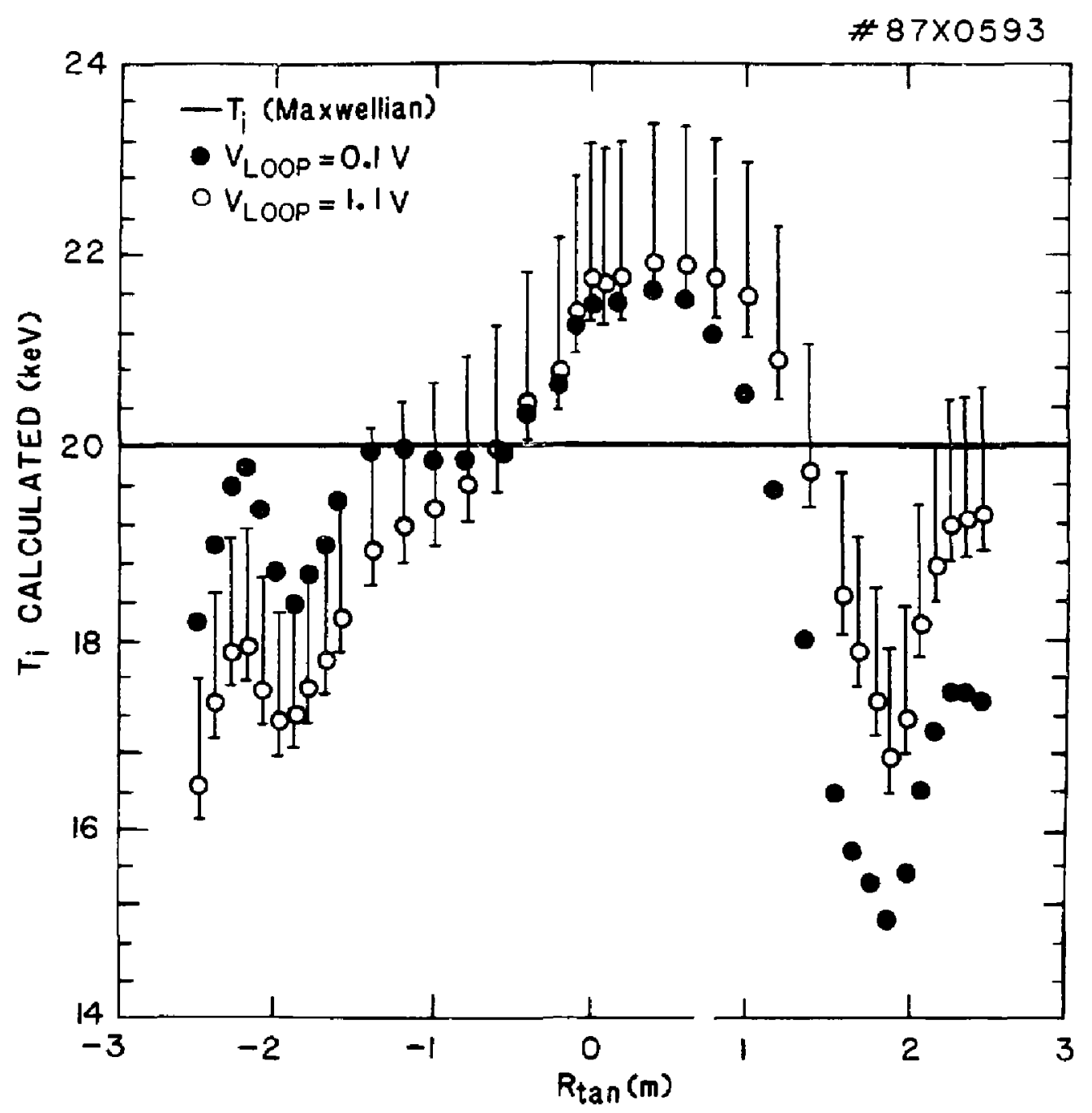

Fig. 15 

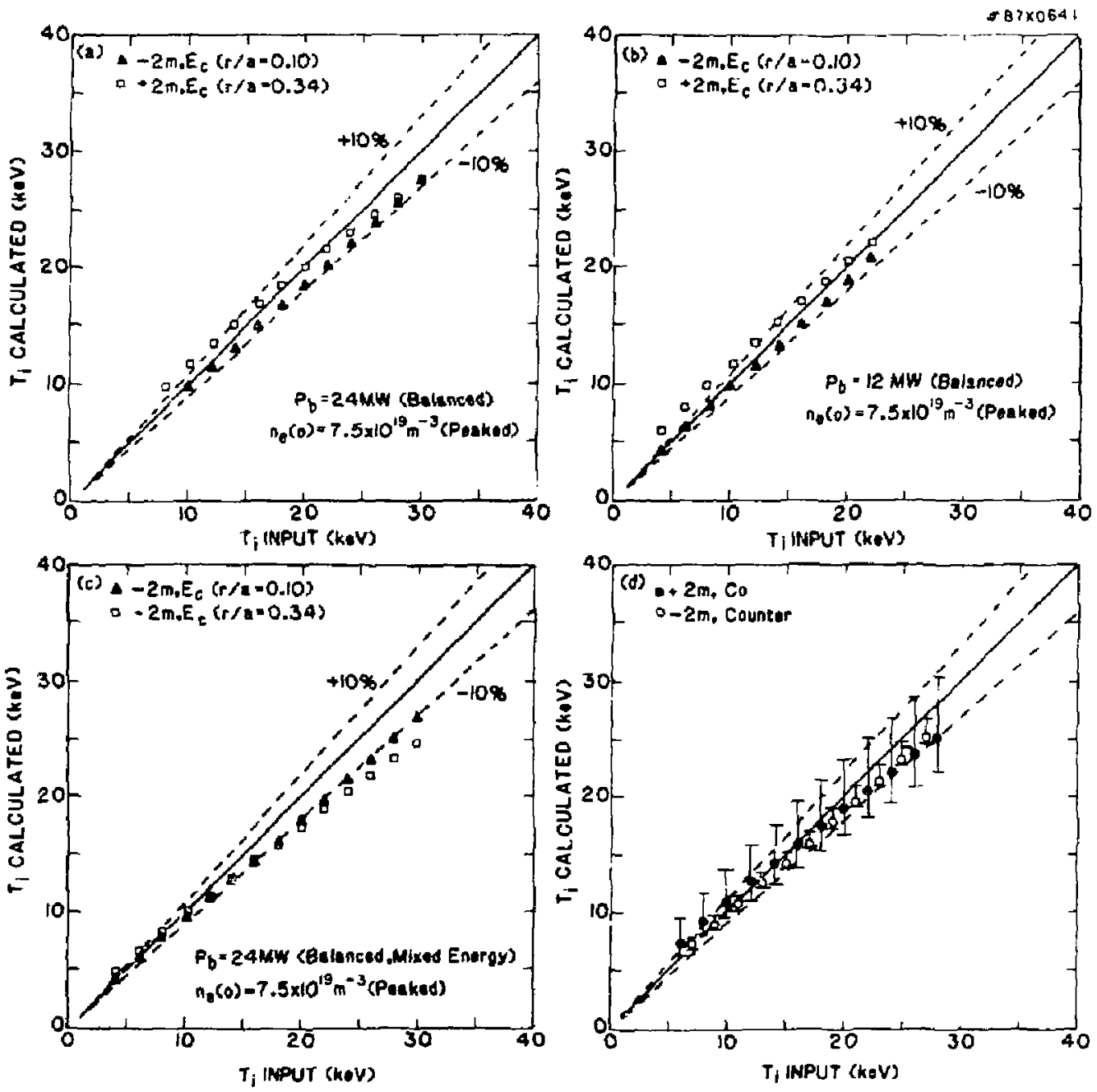

Fig. 16 


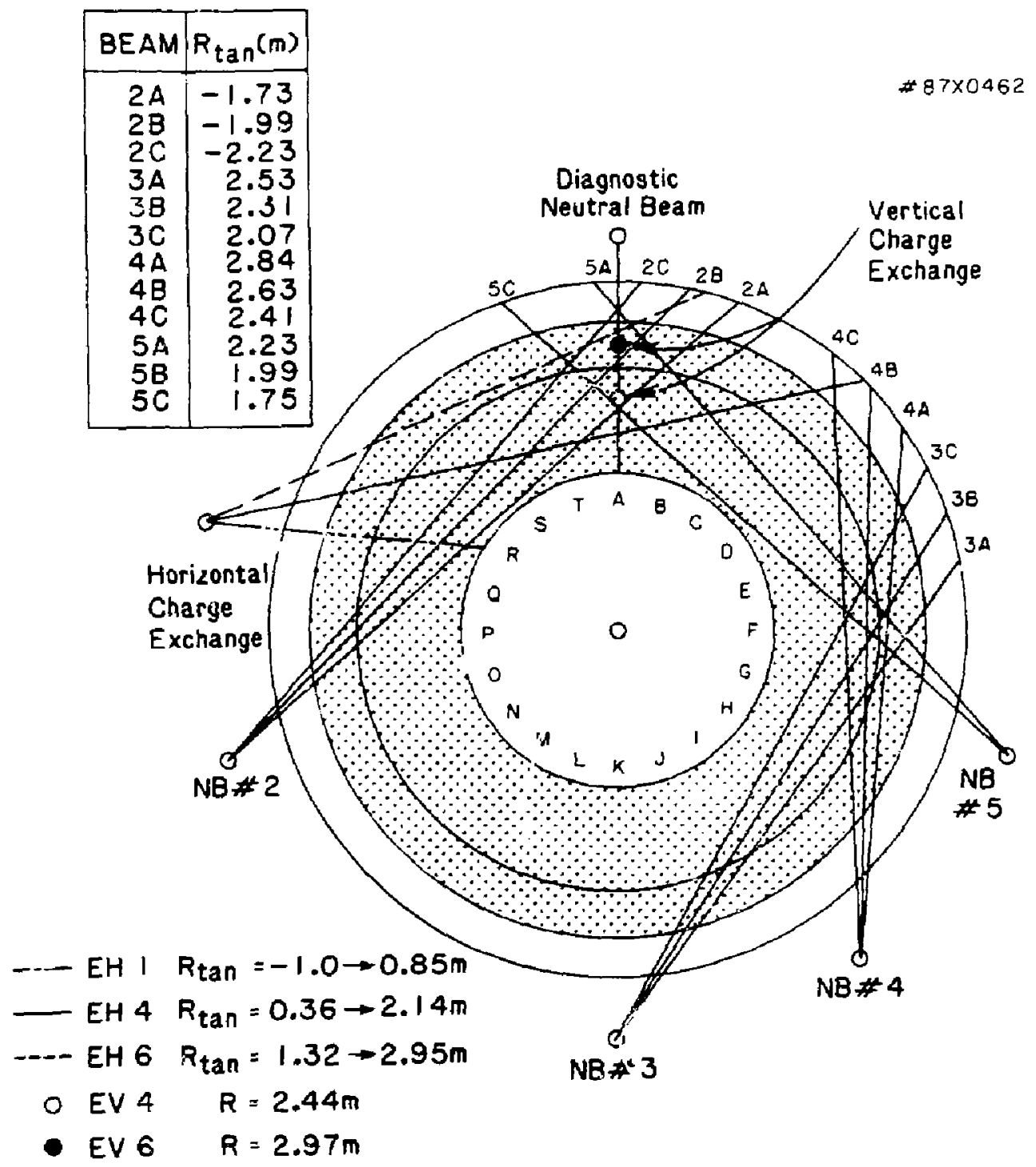

Fig. 17 


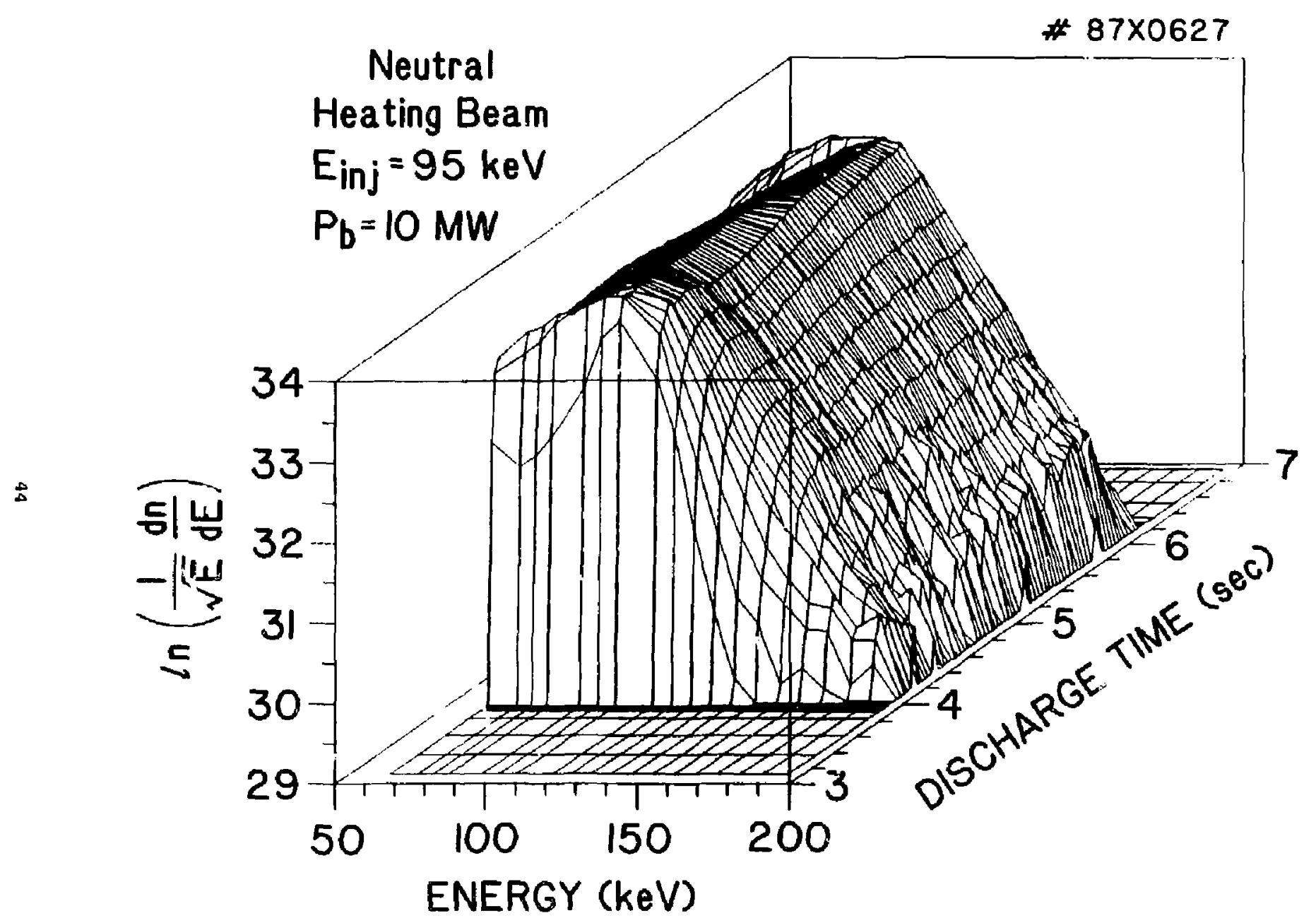




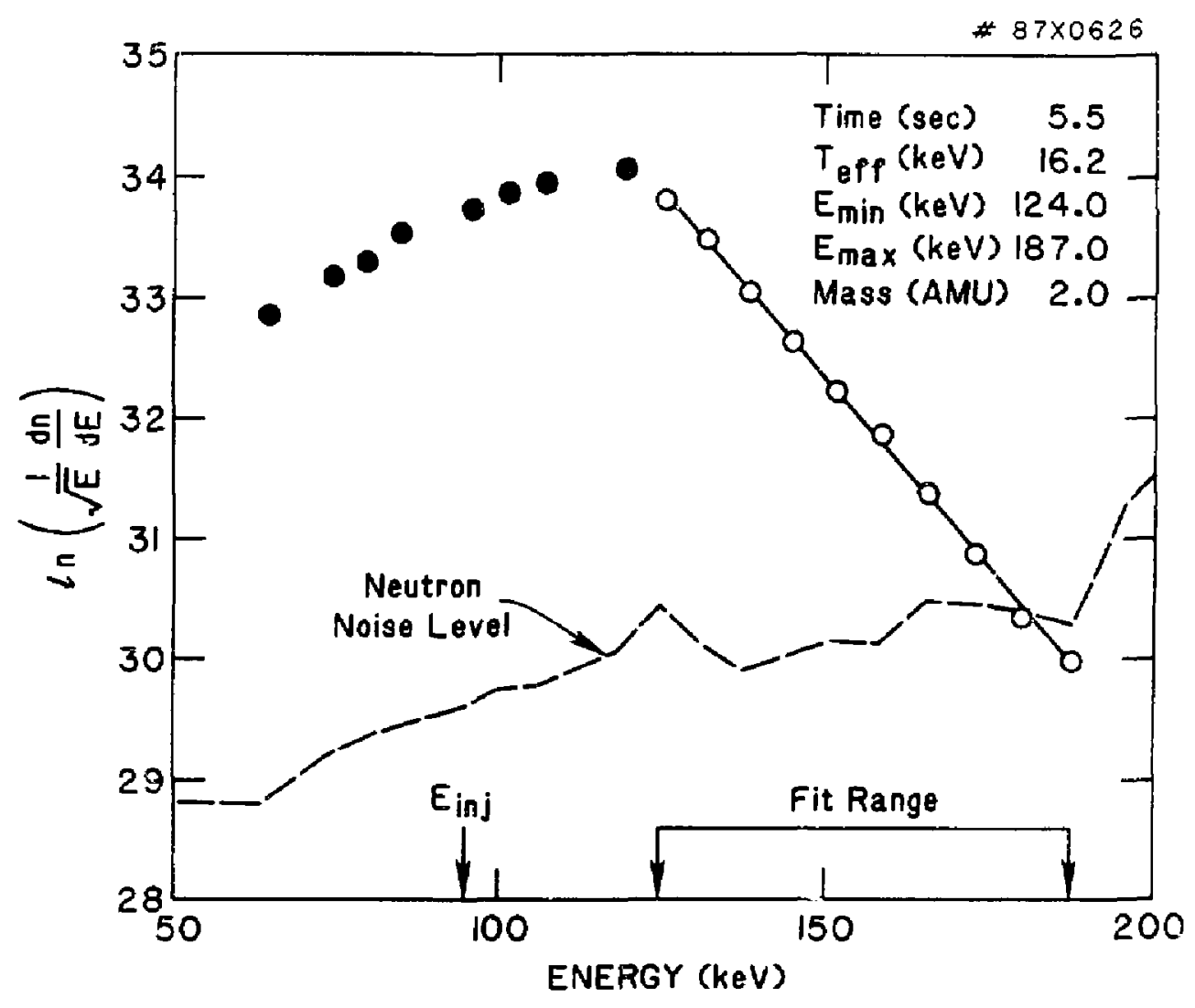

[ig. 19 


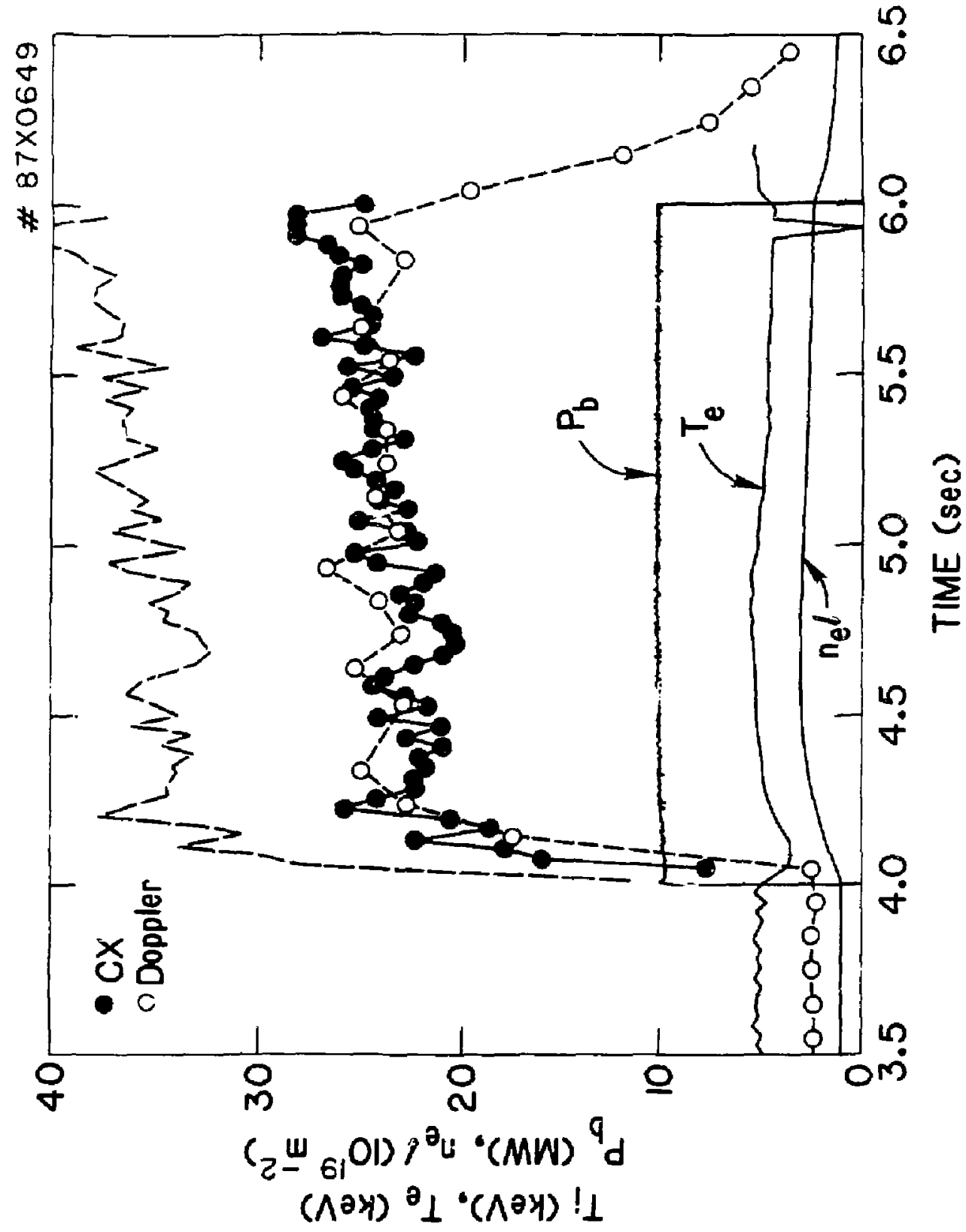




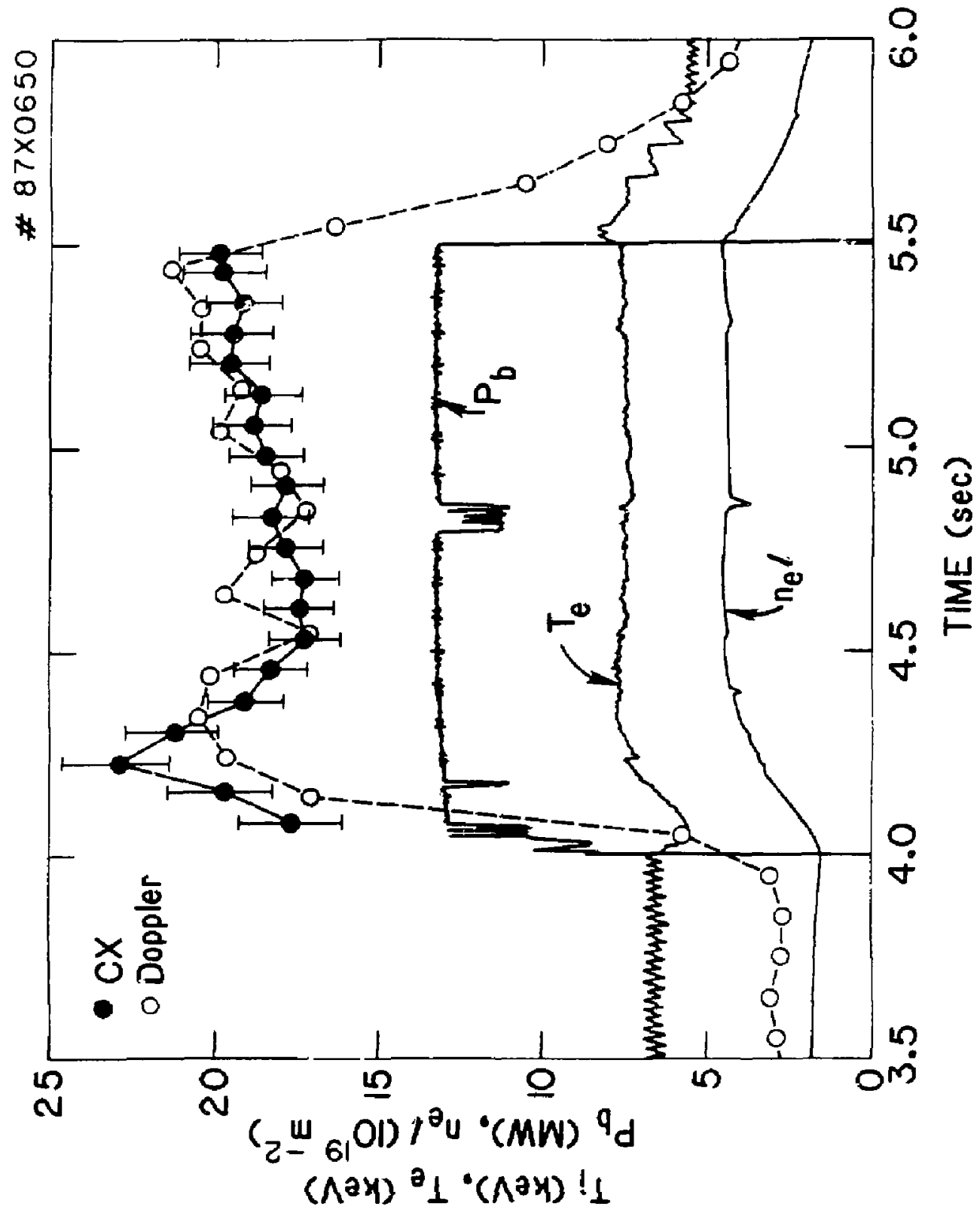




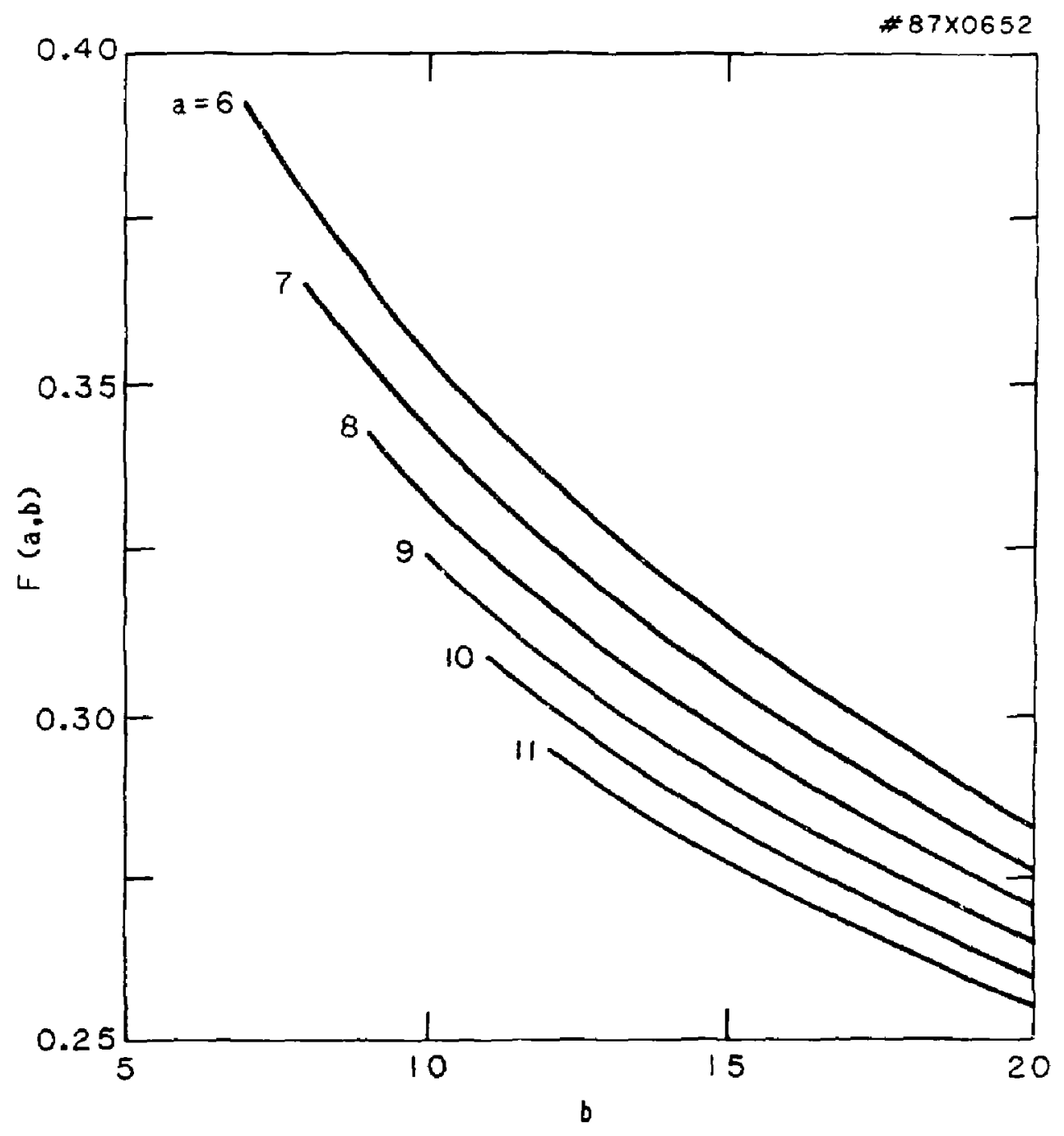

Fig. 22 
Or. Frank I. Paotonl, Unlv of wollongong, AUSTRAL:A Prof. M.H, Brennan, Unty Sydney, AUSTRAL IA

Plasma Rusearch Lab, Austral Ian Not, Univ., AUSTRALIA

Prof. 1.R. Jones, FIInders linlv... AJSTRAL IA

Prot. F. Cap, Inst Theo Phys, AUSTRIA

Prot. M. Helndler, tnstltut tur Theoretiseha Physik, AUSTRIA

M. Goossens, Astronomisch Instltuut, BELGIUH

Ecolo Reyale Mliltalre, l.ob de Phys Plosmas, BELGIUM

Com. of European, Dg XII Fuslon Prog, Belgium

Prot. R. Bouclque, Laborator lum voor Natuurkunde, BELGIUA

Dr. P.H. Sakanaka, Unlv Estudual, BRAzIL

instituto do Posquisos Espoclesi-IHPE, BRMIL

LIbrary, Atomle Enorgy of Canede L Inlter, CMNADA

Or. M.P. Bachynskl, MPB Tochnologles, Inc., CNAOA

Dr. H.M. Skarsgard, Unlv of Saskatch wan, CAMNAA

Or. H. Barnard, Unlversity of British Columbla, CNNADA

Prof. J. Telchnann, Unlv. of Montrest, CANADA

Prof. S.R. Sreenivasun, UnIversity of Colgory, CANADA

Prot. Tudor W. Jahnston. INRS-Energls, CNWAA

Or. C.R. Jemes, UnIr. of Alborta, CNAMOA

Dr. Poter Lukac, Komonskeho Unlv, CZEGrosLOVAKIA

The Librarlan, Culham Laboratory, EHGLANO

Mrs. S.A. Hutehinson, JET LIbrary, EKGl.AND

c. Houttat, Lab. de Physlaue des M!llenx lonlsós, FRANCE

J. Radot, CEN/CNDMANGHE - Bot 506, FRANCE

Or. Tom Mudol, Aeodemy Blbl lographle, HOtG KONG

Proprint Library, Cent Ros Inst Phys, huNangr

Or. B. Dasgupta, Saha Inst, INDIA

Or. R.K. Chhajlanl, VIkran Univ. IRDIA

Or. P. Kar, Instltute for Plasina Resworch, INDIA

Dr. Phillip Rosenau, Israel Inst Tech, ISRAEL

Prof. S. Cuperman, Tel Aulv Untversity, I SRAEL

Librarlan, Int'I Ctr Theo Phys, I TALY

Brof. G. Rostagnl, Unly ol Padove, ITAly

Hiss Chollo Do Polo, Assoc EURATOH-ENEA, ITALY

BIbllateca, del ONR EURATOH, ITALY

Or. H. Yamato, Tasnito Res a Oev, JNPN

Prof, 1. Kavakanl, Mtomic Energy Ros. Institut*, JNPAN

Prot. KyoJl NIshlkase, Unlv of HIroshIma, JAPAN

DIrac, Dept. 19. Tokemak Res. JAERI, JAPAY

Prot. Satoshl Itoh, Kyushu Unlversity, JAPAH

Raseareh info Conter, Nagoyo UnIvarsity, JAPAH

Prof, 5. Tonako, Kyoto UnlversIty, JAPAY

LI brary, Kyato UnIvers Ity, JAPAN

Prot. Nobuyukl Inoue, Unfversity of Tokyo, SAPAN

5. Morl, JAERI, JAPAN

M.H. KIm, Kores Advanead Energy Resmareh linstItute, KOREA

Prot. D.I. Cnel, Adv. Inst Sel \& Tech, KOREA

Prot, B.S. LIIN, Unluersi py of Wolkoto, NEW ZEALAWD

Instltute of Plasina Physles, PEOPLE'S REPUBLIC OF CHINA

Librarlan, Institute of Phys., PEOPLE'S REPUaLIC OF CHINA

LIbrary, Tslng Hua Ualverslty, PEOPLE'S REPU⿴lic OF CHIMA
Z. LI, Southwost inst. Physles, PEOPLE'S REPUBLIC OF CHINA Prot. J.A.C. Cabral, Inst Superior Tecn, PORTUGAL Dr. Octavion Potrus, AL I CUZA Unlversity, ROMANIA Dr. Johan do VIlllers, Plasme Phystcs, AEC, SO AFRICA Prof. M.A. Hell berg, University of Natal, SO AFRICA Fusion DI.. Llbrary. JEN, SPAIN

Dr. Lennart Stonflo, Unlversity of UMEA, SWEDEN Library, Royal I nst ToCh, SWEDEN

Prof. Hans Wl thalmsan, Chalmars unir Toch. SwEOEH

Centro Phys des Plesmas, Ecolo Polytech Fed, SHITZERLANO Blollopheak, fom-inst Yoor Plasma-Fysico, THE NETMERLANDS Or. 0.0. Ryutor, Slbarlan Acad Sel, USSR

Dr. G.A. EIIseev, Kurchitor Instituto, USSR

Dr. V.A. Glukhlkh, inst Electromphyslcal, USSR

Dr. V.T. Tolok, Inst. Phys. Tech. USSR

Dr. L.M. Kovrizhnykh, Instlitute Gan. Phy-iles, USSR

Prot. T.J.M. Boyd, Univ College N Wales, WALES

Nuclear Res. Establishment, Julleh Lid, W* GERMaNY Bibllothek, Inst. Fur Plasmatarschung, W. GERMawr Or. K. SchIndlar, Ruhr UnIvarsitat, W. GERMAnY ASOSX Roading fom, IPP/Max-PIanck-institut fur

Plosnaphyslk, W. GERMAHY LI lorerian, Max-Planck Institut, W. GERMN, Prof. R.K. Janer, Inst Phys, rugoslavil 